كيفية أداء نوكتورن رقم (1) للفيولينة والجيتار عند فريدريش برجمولر

\title{
Friedrich Burgmüller
}

أ. أ.دد/ محمد حمدى عبد الفتاح

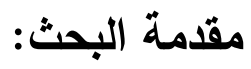

مؤلفة النوكتورن Nocturne مقطوعة موسيقية توحى ألحانها بالهدوء والثاعرية وذات أسلوب

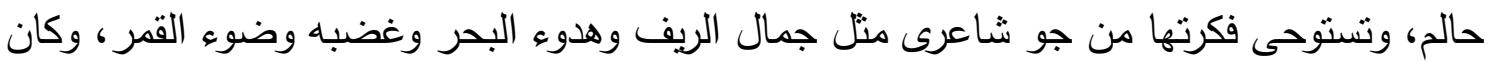

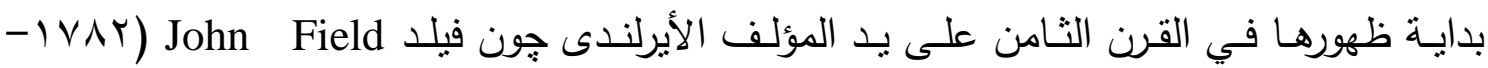

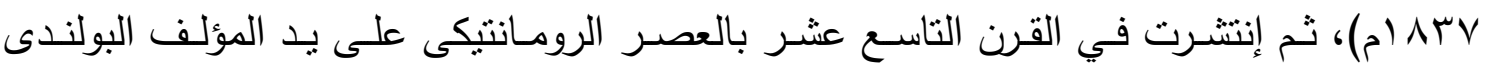

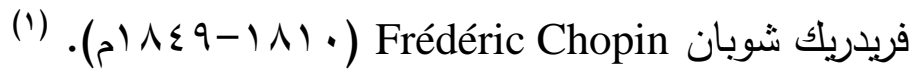
وآلة الجيتار Guitar آلة نبر وترية من أصل عربي "المغرب العربي" تمثاز بأداء الأربيجات

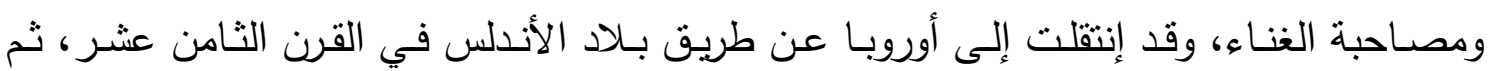

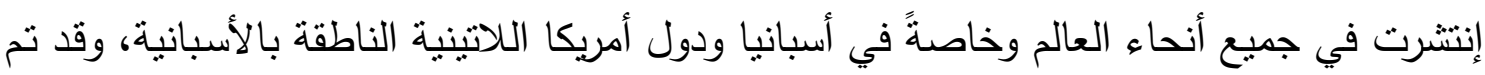

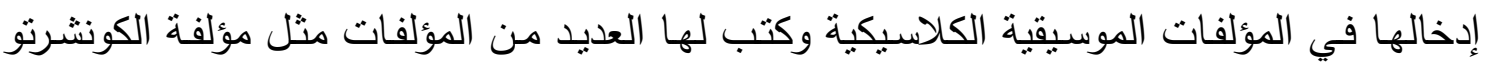

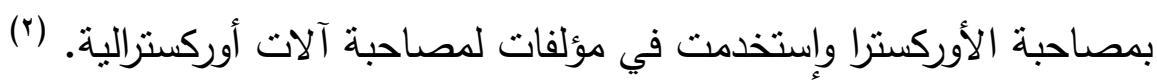
وسوف يتتاول هذا البحث مؤلفة نوكتورن Nocturne رقم ( ) لآلّة الفيولينة وآلّة الجيتار Fiolin and Guitar ع ع (AV) والتى قام بنشرها في مدينة لييزج Leipzig بألمانيا.

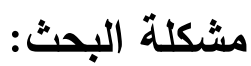

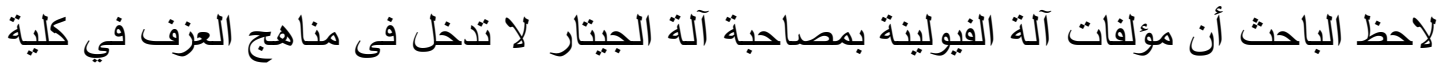

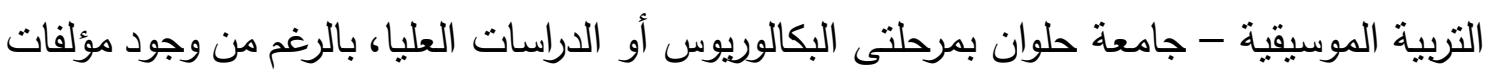

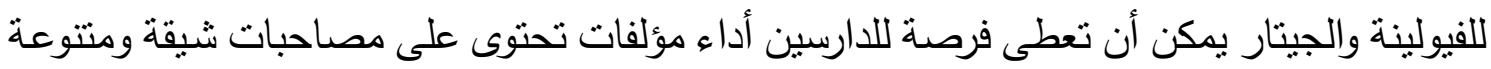

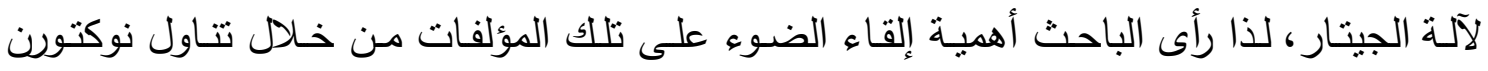
الفيولينة والجيتار عند فريدريش برجمولر بالدراسة والنحليل.

• أستاذ مساعد بقسم الأداء - شعبة أوركسترالي - كلية التربية الموسيقية - جامعة حلوان.

(1) Sadie, Stanly: "The New Grove Dictionary of Music and Musician", Macmillan Publishers Limited, U.S.A, 2001, P.155.

(2) Achard, Ken: "The History and development of the American Guitar", Bold Strummer Press, U.S.A, 1996, P.15.

مجلة علوم وفنون الموسيقى - كلية التربية الموسيقية ـ المجلد الرابع والأربعون - 
1- التعرف على الخصائص الفنية للنوكتورن رقم ( ) للفيولينة والجيتار عند فريدريش برجمولر . r- التوصل إلى كيفية أداء نوكتورن رقم ( ) للفيولينة والجيتار عند فريدريش برجمولر .

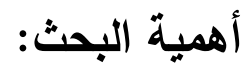

إضافة علمية لمؤلفات عالمية لآلة الفيولينة بمصاحبة آلة الجيتار إلى مناهج عزف الفيولينة

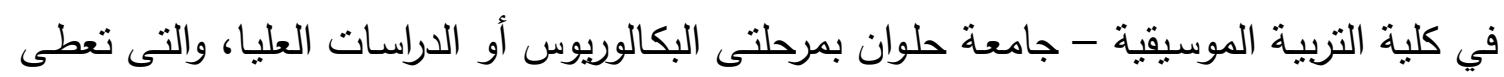

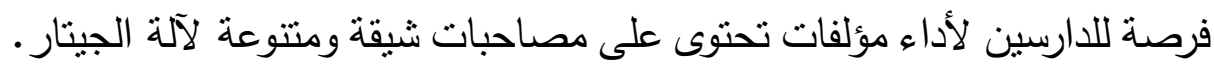

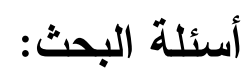

1- ما الخصائص الفنية لنوكتورن رقم ( ) للفيولينة والجيتار عند فريدريش برجمولر؟ r- ما كيفية أداء نوكتورن رقم (1) للفيولينة والجيتار عند فريدريش برجمولر؟

إجراءات البحث:

أ) منهج البحث:

يتبع البحث المنهج الوصفي "تحليل المحتوى"، وهو المنهج الذي يقوم على وصف الظاهرة

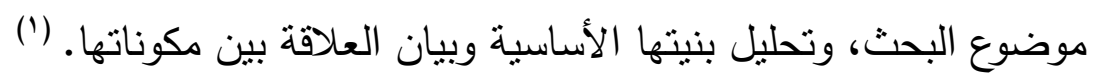

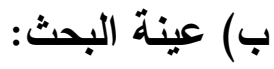

r نوكتورن Nocturnes للفيولينة والجيتار Violin and Guitare عند فريدريش برجمولر والتى نشرها في لييزج بألمانيا، وقد قام الباحث بإختيار النوكتيورن رقم (1) كعينة بحث. ج) حدود البحث:

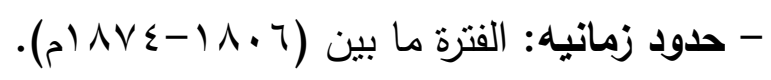
- (دود مكانيه: ألمانيا.

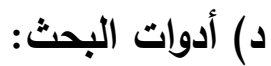

المدونة الموسيقية لعينة البحث، المراجع العربية والأجنبية والإنترنت.

(1) آمـال صـادق وفؤاد أبو حطب: "مناهج البحث وطرق التحليل الإحصائي"، مكتبة الأنجلو المصرية، القاهرة

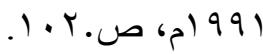

مجلة علوم وفنون الموسيقى - كلية التربية الموسيقية ـ المجلد الرابع و الأربعون -

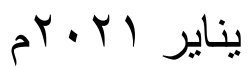


1- أسلوب الأداء Performance Style:

الصفه المميزة للمؤلفة الموسيقية والنى تعبر تعبيراً واضحاً عن الغرض الذى يريده المؤلف،

والصفات المميزة لأسلوب المؤلف. (1)

r ب - مقطوعة حالمة

مؤلفة موسيقية آلية رومانتيكية ليس لها قالب محدد، وموسيقاها توحي بجو وهدوء الليل، بمكن

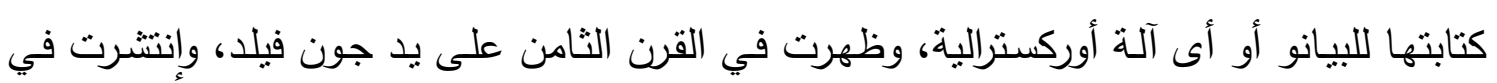

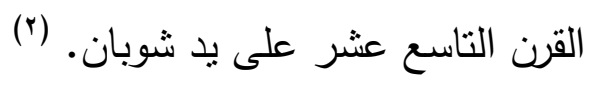

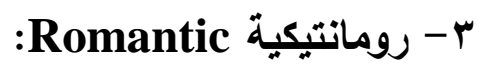

إثتقتت كلمة "رومانتيك" Romantic من كلمة "رومانس" Romance وهي كلمة من اللغة

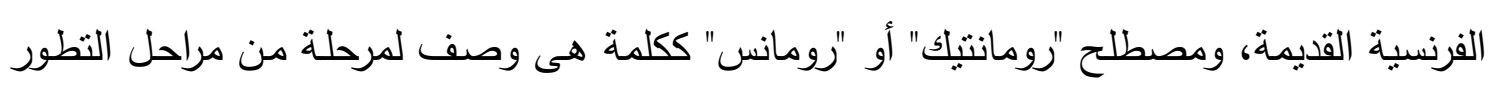

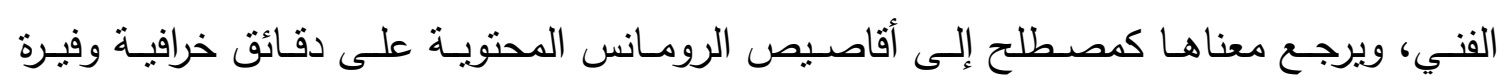

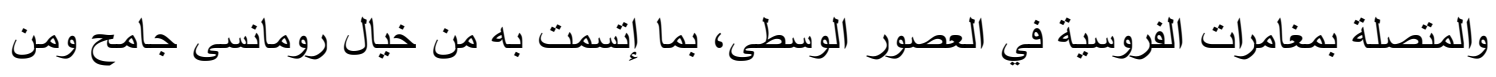

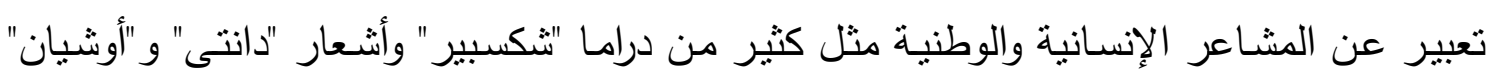

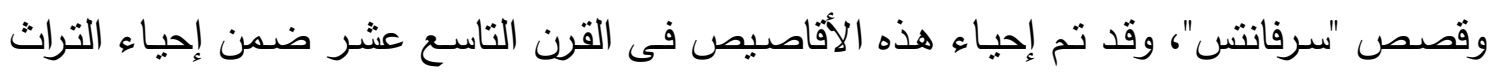

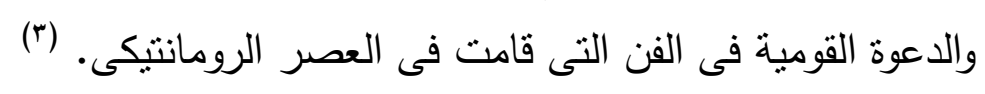

الاراسات السابقة المرتبطة بموضوع البحث الراهن:

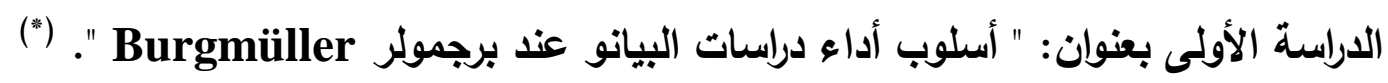

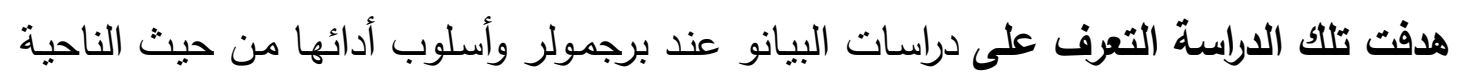

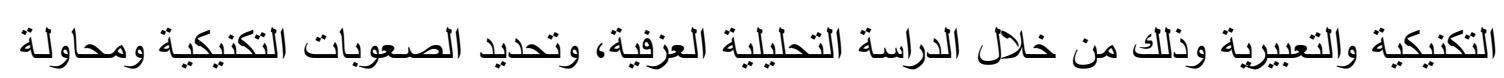
تنليلها بالإرشادات العزفية للوصول إلى الأداء الجيد، وتتاولت حياة برجمولر وأسلوبه في التأليف

(1) Randel, Michael: "The Harvard Concise Dictionary of Music and Musicians",

Harvard College Press, U.S.A, 1999, P.407.

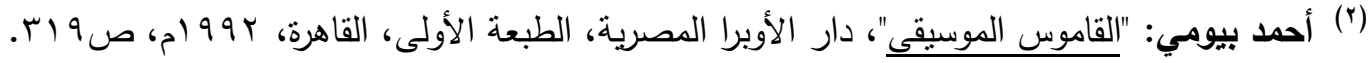

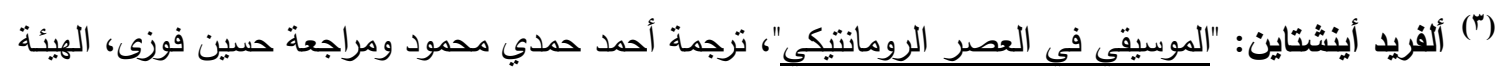

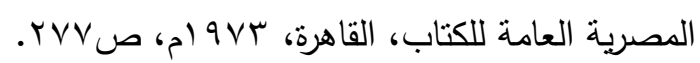

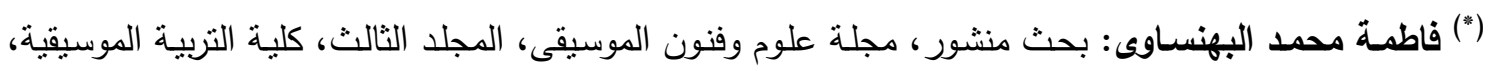

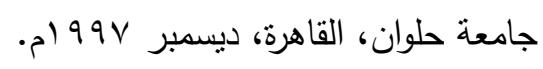

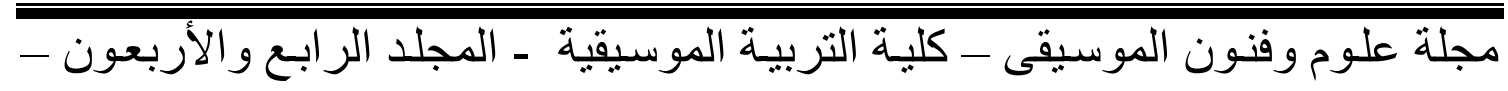

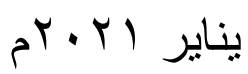


ومؤلفاته للبيانو ، وترتبط تلك الاراسـة بالبحث الراهن من حيث تتاول مؤلف عينة البحث الراهن

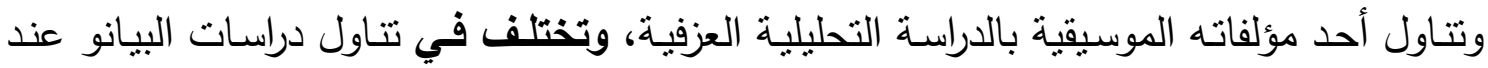
برجمولر، بينما يتناول البحث الراهن نوكتورن رقم ( () للفيولينة والجيتار عند فريدريش برجمولئ . الاراسـة الثانيـة بعنـوان: " نوكتورن في ثـلاث مشــاهد مصنف (VY) لآلـة البيـانو عند سـليم

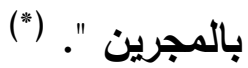
هدفت تلك الدراسـة التعرف على أسلوب أداء مؤلفة نوكتورن (VY) عند سليم بالمجرين من خلال التحليل البنائي والعزفي لها، وتحديد الثقنيات العزفية التي تشتمل عليها المؤلفة والعمل على

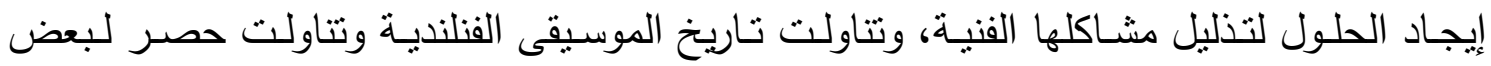
مؤلفات نوكتورن البيانو وحياة سليم بالجرين وأعماله للبيانو، وترتبط تلك الدراسـة بالبحث الراهن

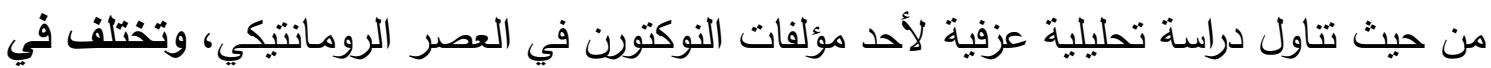
تتاول نوكتورن البيانو مصنف (VY) عند سليم بالمجرين، بينما يتناول البحث الراهن نوكتورن رقم ( ) للفيولينة والجيتار عند فريدريش برجمولر ل

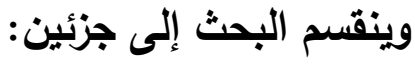
الجزء الأول: الإطار النظري ويشتمل على البنى

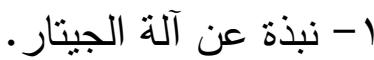

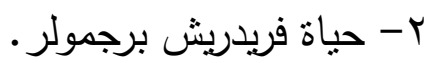
r- مؤلفات برجمولر للآلات الوترية. الجزء الثاني: الإطار التطبيقي ويشتمل على برانى

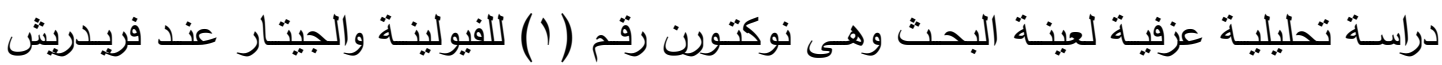
برجمولر، وتحديد التقنيات العزفية باليدين وتوضيح كيفية أدائها.

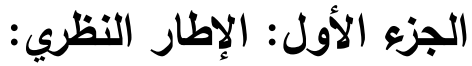

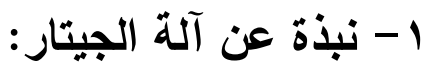

هى آلة نبر وترية تتكون من صندوق مصوت رنان من الخشب ومسطح من الجبهتين منصل

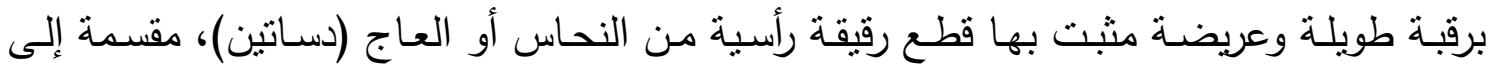

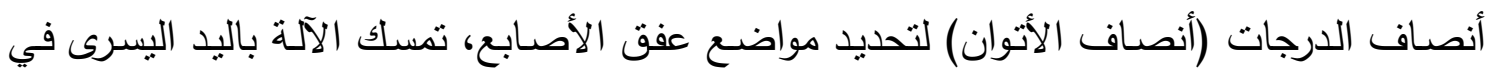
(") شيماء حمدى عبد الفتاح: بحث منشور ، مجلة علوم وفنون الموسيقى، المجلد التاسع والعشرون الجزء الأول، كلية التربية الموسيقية، جامعة حلوان، القاهرة، يونيو ع الـ بام.

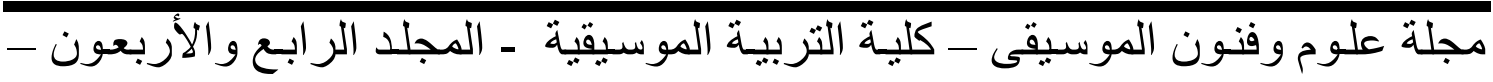

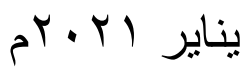


وضع أفقي ويعزف عليها بجذب الأوتار بأصابع اليد اليمنى عدا الإصبع الأصغر الذى ينركز

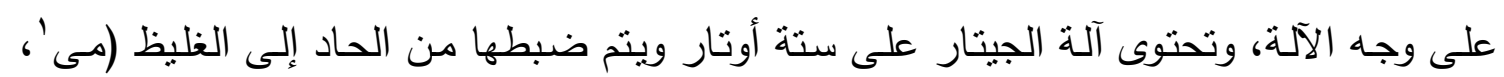
سى، صول، رى، لا، مى) وتدون أصواتها على مفتاح (صول) ونطاقها الصوتى "ثلاثة أوكتافات"

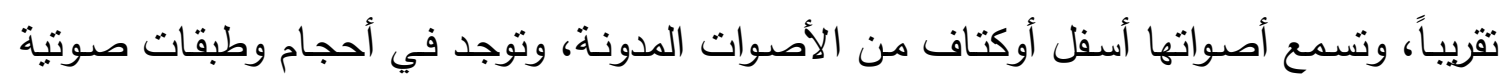

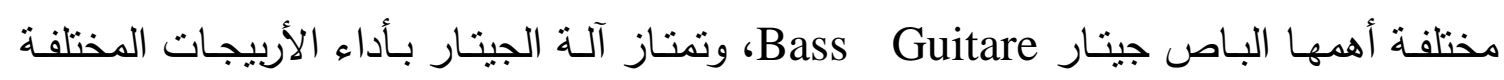

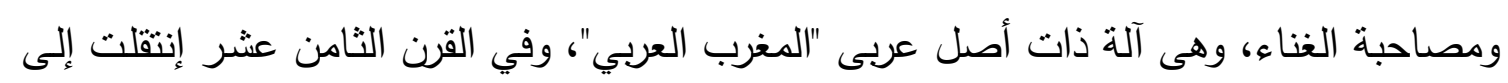

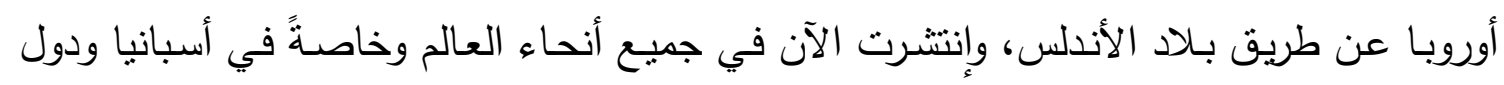

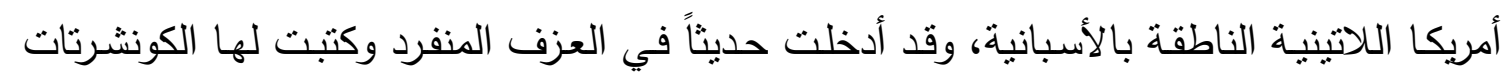

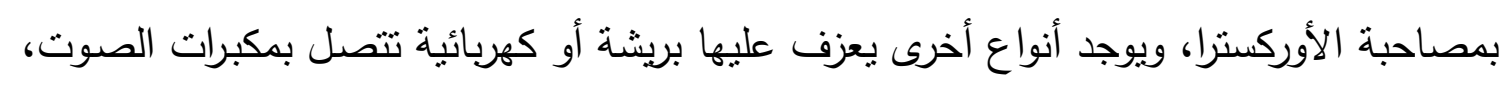

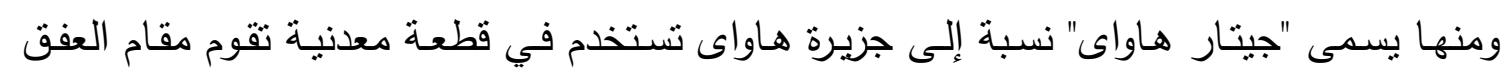

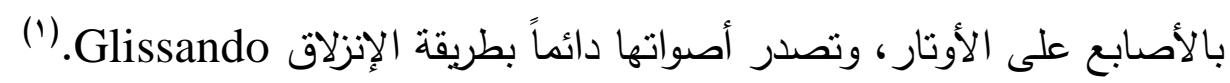

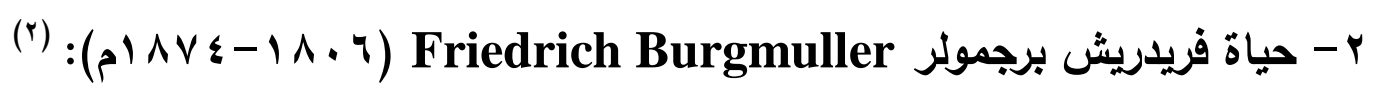

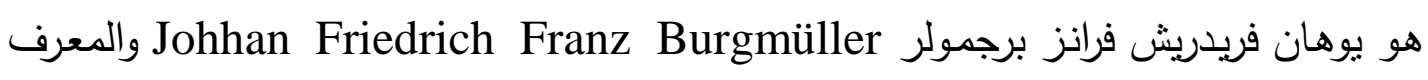

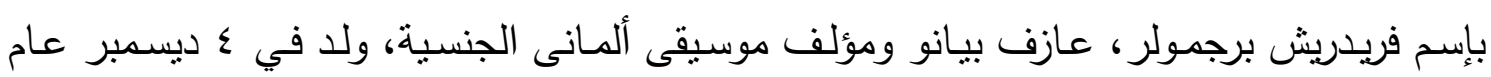

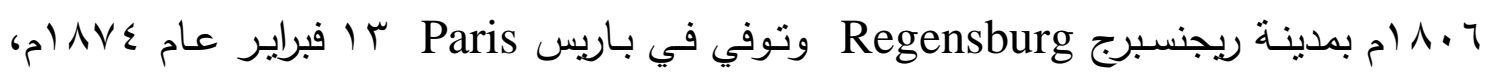
ووالده هو فريدريش أوجست برجمولر Friedrich August Burgmüller مؤلف موسيقى، بوني،

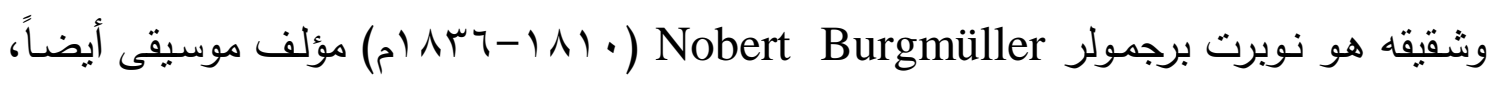

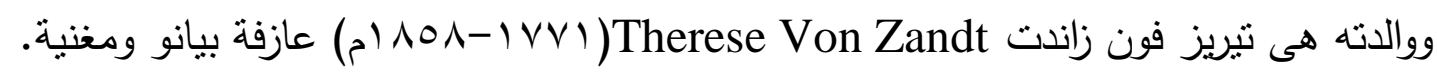

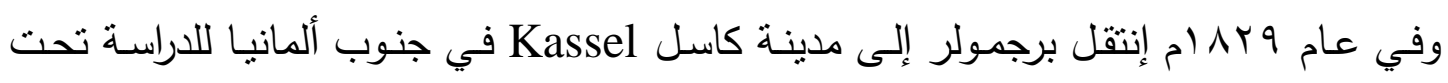

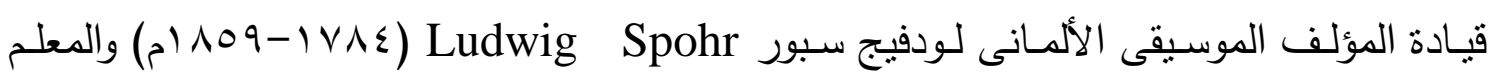

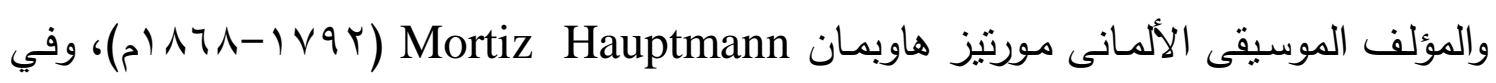
ع ا يناير ظهر كعازف بيانو في حفلته الأولى في ألمانيا.

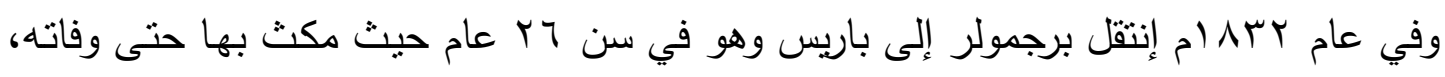
وبالرغم من أن أخيه نوبرت وضع خطة لكى يمكث أخيه برجمولر معه في باريس، ولكن أخيه

(1) Achard, Ken: "The History and development of the American Guitar", Bold Strummer Press, U.S.A, 1996, P.15.

(2) Apel, Wille: "Harvard Dictionary of Music", Second Edition, the Belknap Press of Harverd University Press, Cambrige, London, 1979, P.464.

مجلة علوم وفنون الموسيقى - كلية التربية الموسيقية ـ المجلد الر ابع و الأربعون -

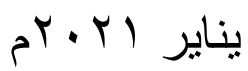


توفى غارقاً في منتجع صحي في عام Aro ام، وفي باريس تأثر برجمولر بالموسيقى الفرنسية

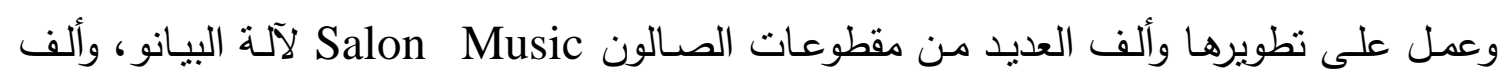

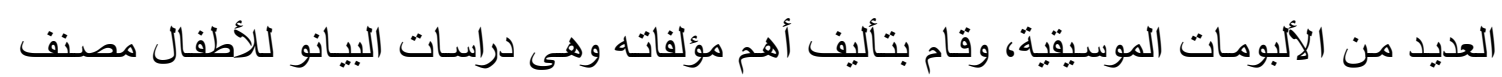

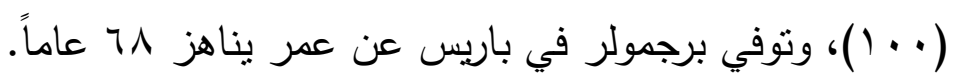

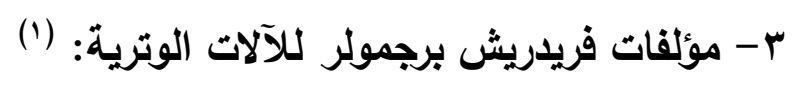

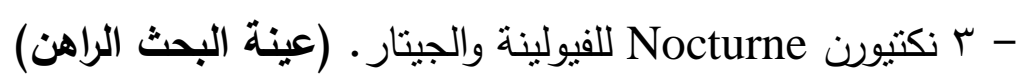

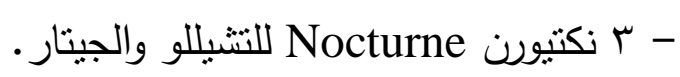

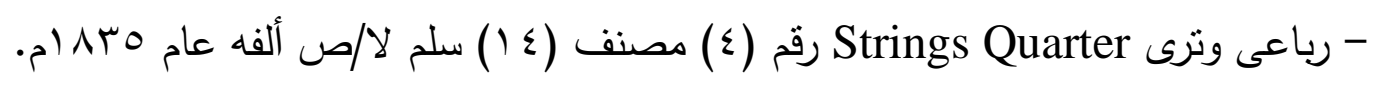
الجزء الثاني: الإطار التطبيقي: - التئي

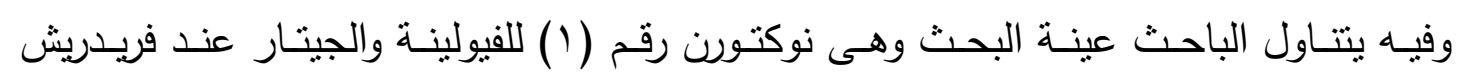

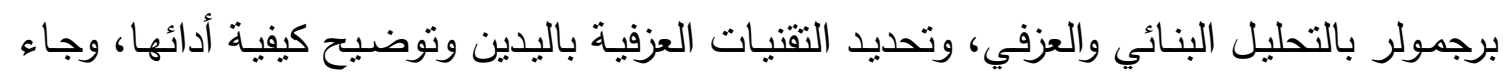
النحليل البنائى والعزفى للنوكتورن رقم ( (1) كما يلي:-

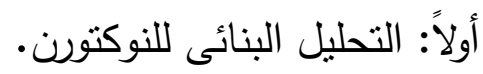

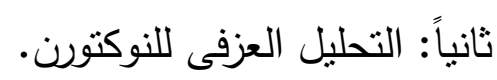
ثالثاً: المصطلات التعات التعبيرية في النوكتورن. رابعاً: التقنيات العزفية في النوكتورن وكيفية أدائها. "النقنيات العزفية باليد الينى فى النوكتورن. " التقنيات العزفية باليد اليبرى فى النوكتورن.

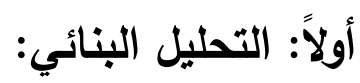

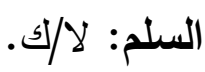

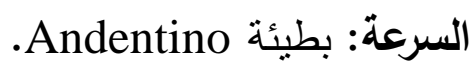
الميزان: 6

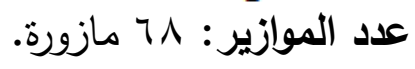

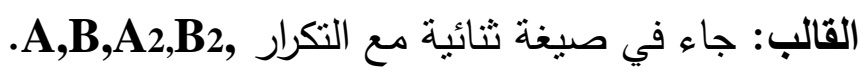
ويتكون من فكرين جاعت على النحو النالى:

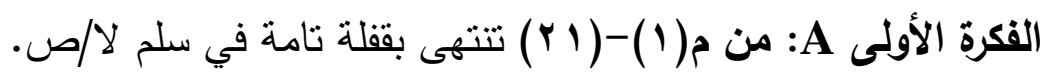

(1) Sadie, Stanly: op.cit, 2001, P.144.

مجلة علوم وفنون الموسيقى - كلية التربية الموسيقية ـ المجلد الرابع و الأربعون -

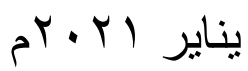


تتكون من جملتين جاءت كما يلي: - الجملة الأولى: من م(1)-(9) تنتهى بقلة على على الدرجة السابعة في سلم لا/ص.

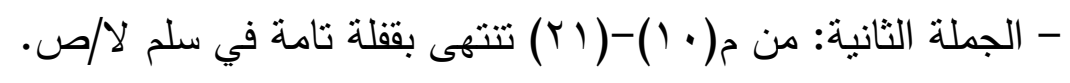

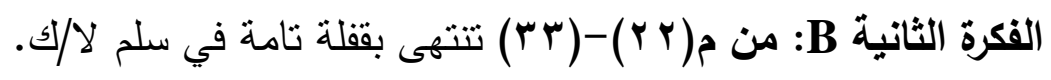
تنكون من ثلاث عبارات جاءت كما يلي:

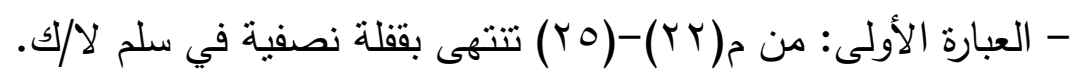

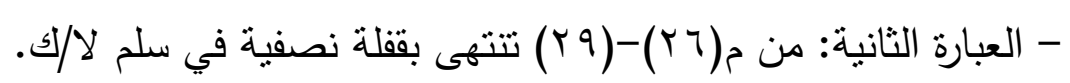

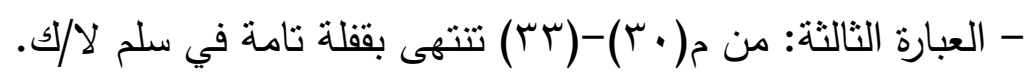

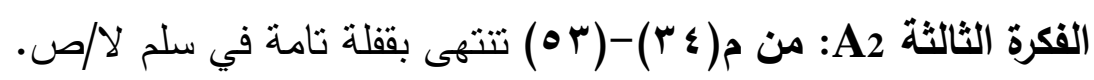
إعادة حرفية للفكرة الأولى وتتكون من جملتين جاءت كما يلي:

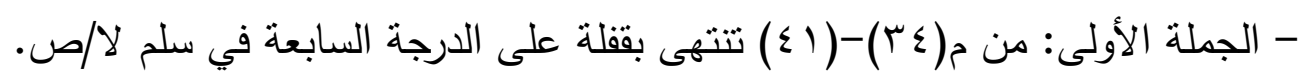

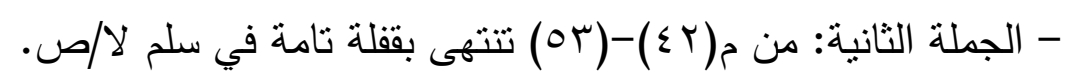

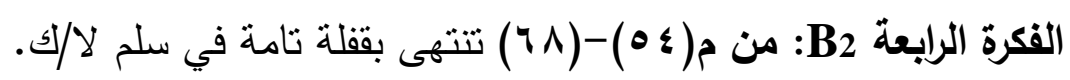

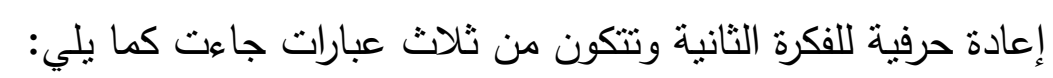

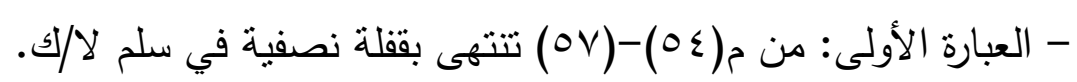

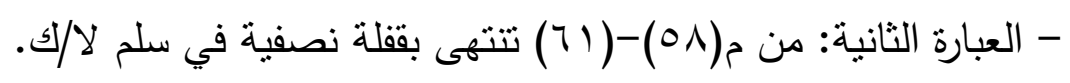

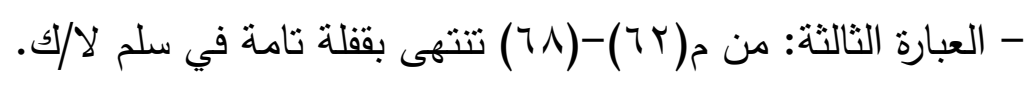
ثانياً: التحليل العزفى.

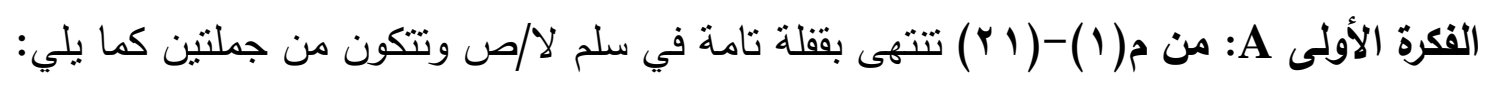

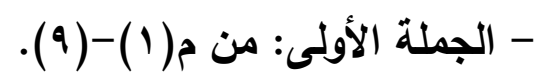

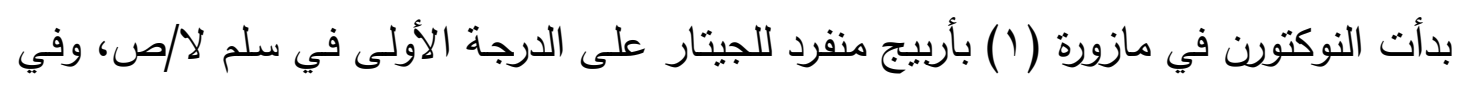

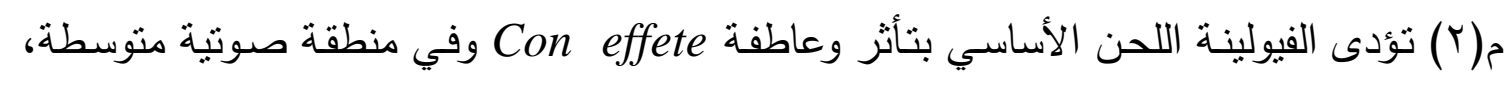

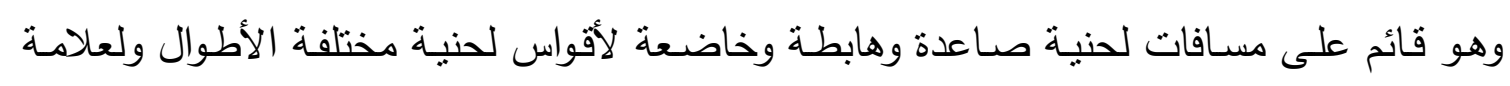
العزف المنفصل Detache (>)، وتنتهى بنغمات مفردة هابطة تسبقها حلية الأبوجاتورا، ويصاحبها

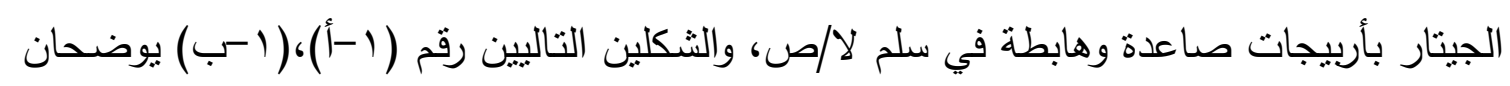
الجملة الأولى بالفكرة الأولى عند كل من الفيولينة والجيتار .

مجلة علوم وفنون الموسيقى - كلية التربية الموسيقية ـ المجلد الرابع والأربعون - بل

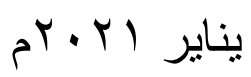




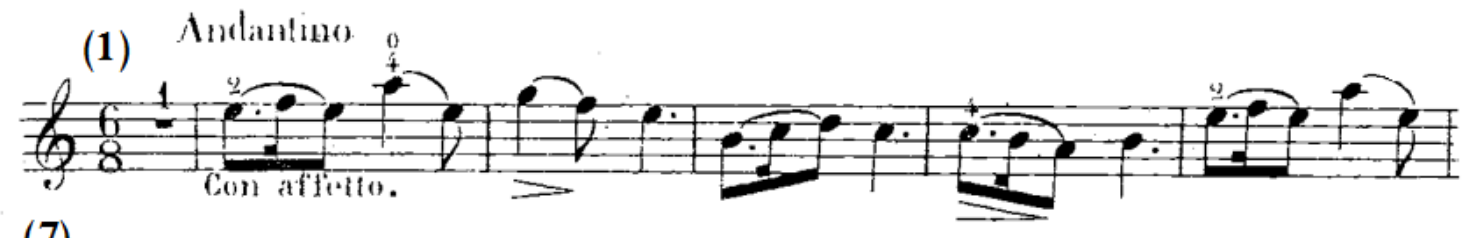

(7)

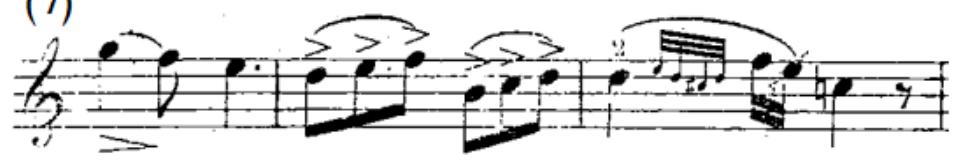

شكل رقم (1-أ)

الجملة الأولى بالفكرة الأولى A من م(1) -(9 (1) عند الفيولينة

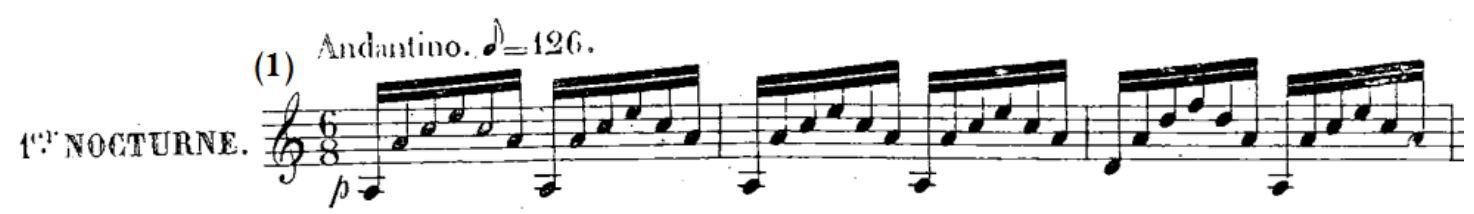

(4)

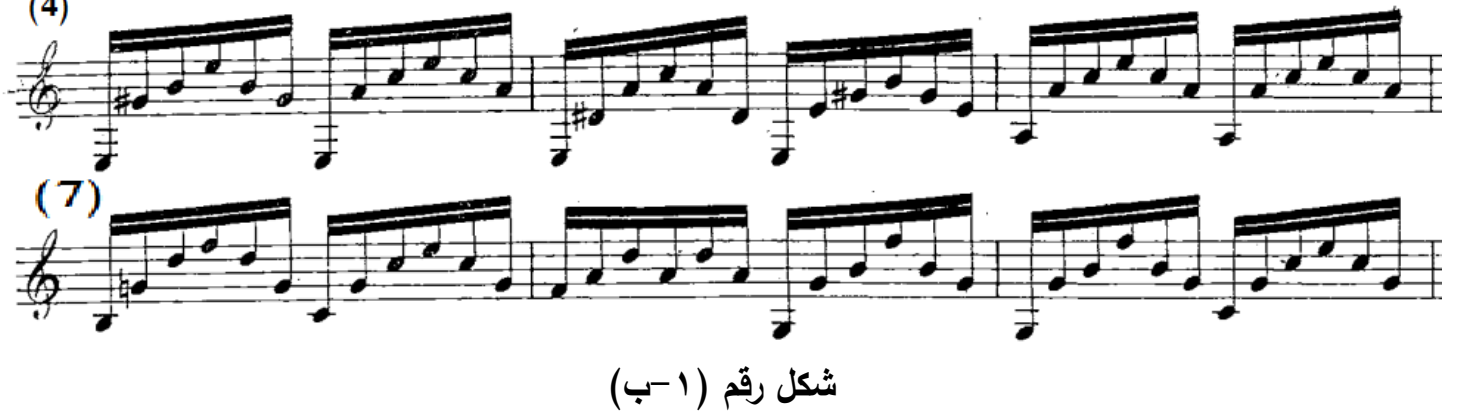

الجملة الأولى بالفكرة الأولى A من م(1) (1) (9) (9) عند الجيتار

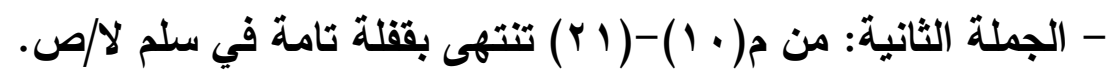

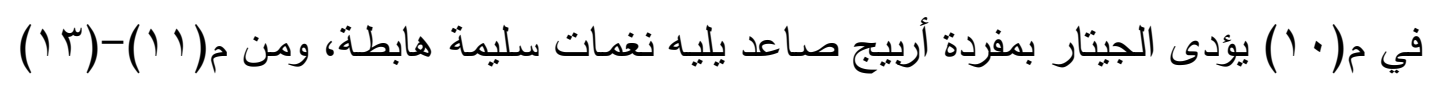

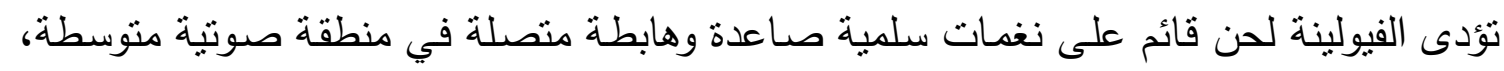
وفي م(ع ( ) يظهر نغمة متكررة ومتقطعة Mezzo Staccato، ومن م(0) 10)-( (Y) تؤدى الفيولينة

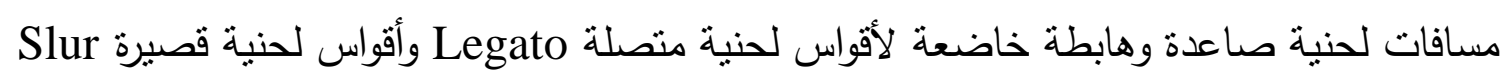

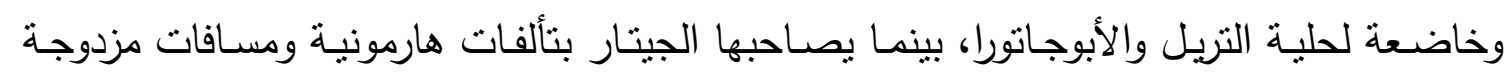

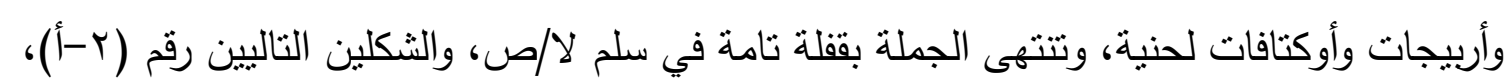
(r-ب) يوضحان الجملة الثانية بالفكرة الأولى عند كل من الفيولينة والجيتار .

مجلة علوم وفنون الموسيقى - كلية التربية الموسيقية ـ المجلد الرابع و الأربعون -

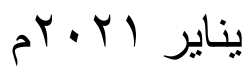


(10)

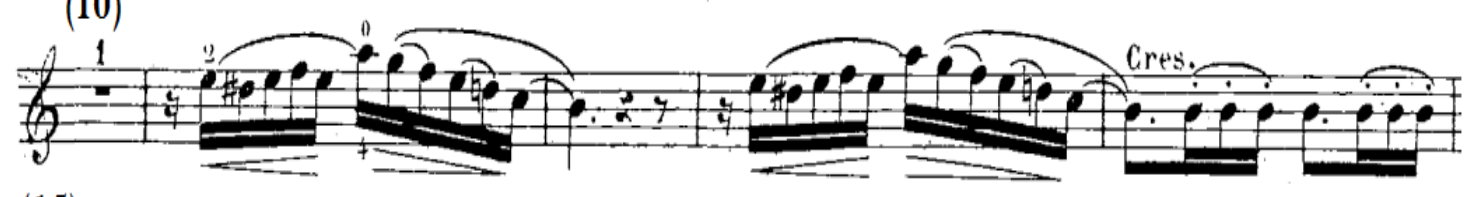

(15)

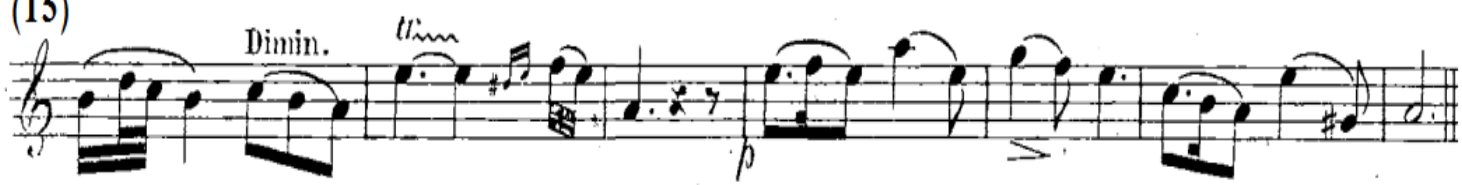

شكل رقم (- (- (أ)

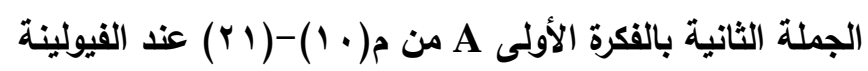

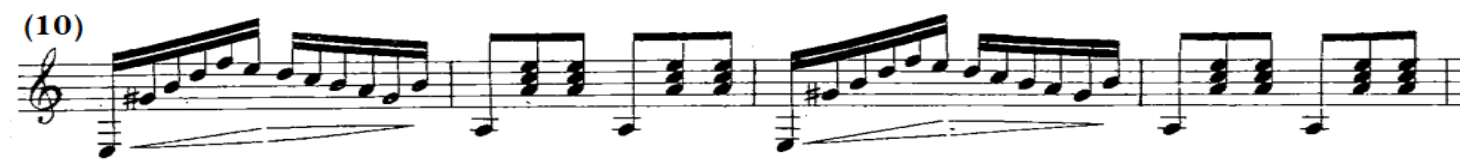

(14)

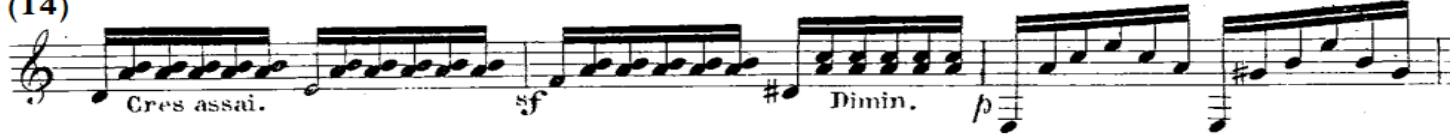

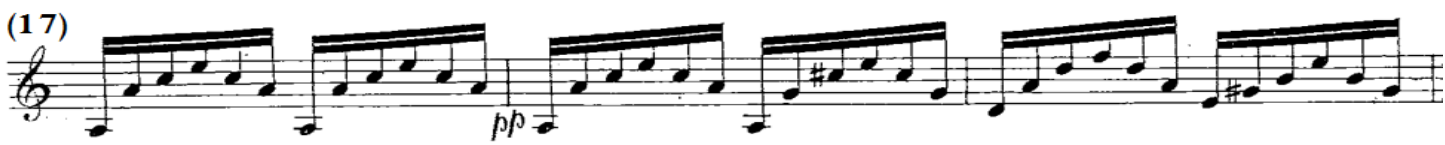

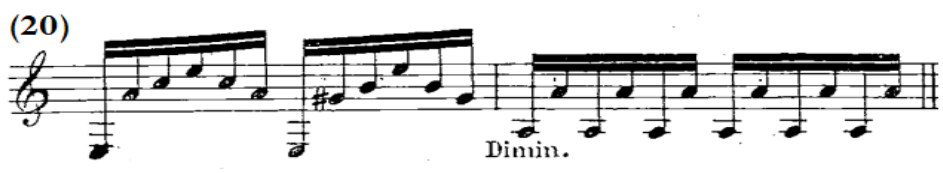

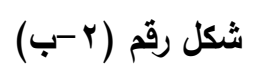

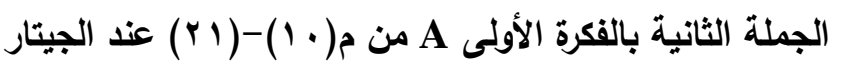

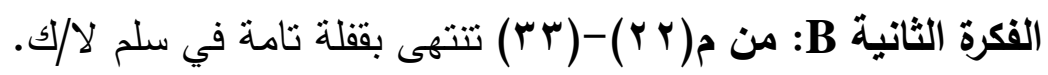
وتتكون من ثلاث عبارات جاءت كما يلي:

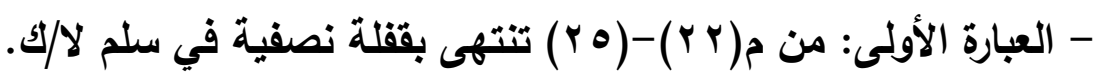

جاء لحن الفيولينة في سلم لا/ك يؤدى بصوت خافت جداً pp وفي منطقة صوتية منخفضـة، وهو قـائم على نغمـات مفردة خاضـعة لأقواس لحنيـة متصـلة Legato، ويسـتمر الجيتـار في المصاحبة بالأربيجات ولكن في سلم لا/ك، وتتتهى الجملة بقفلة نصفية في سلم لا/ك، والشكلين التاليين رقم (r-أ)،(س-ب) يوضحان العبارة الأولى بالفكرة التانية عند كل من الفيولينة والجيتار. (22)

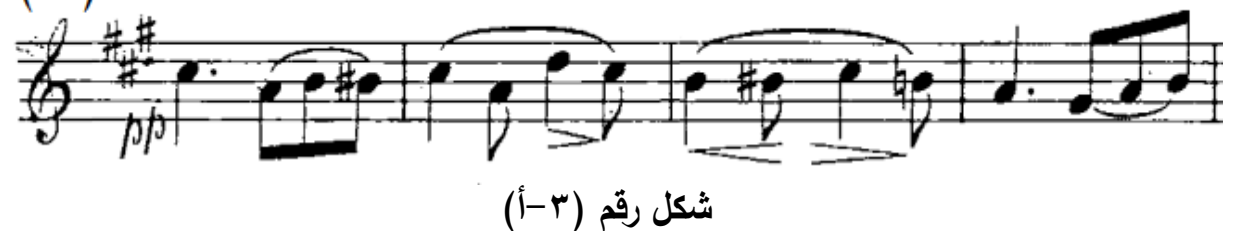

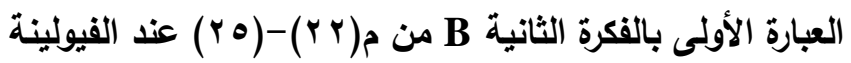

مجلة علوم وفنون الموسيقى - كلية التربية الموسيقية ـ المجلد الر ابع والأربعون -

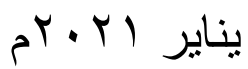




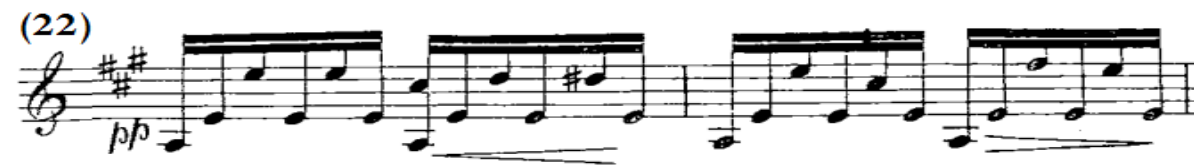

(24)

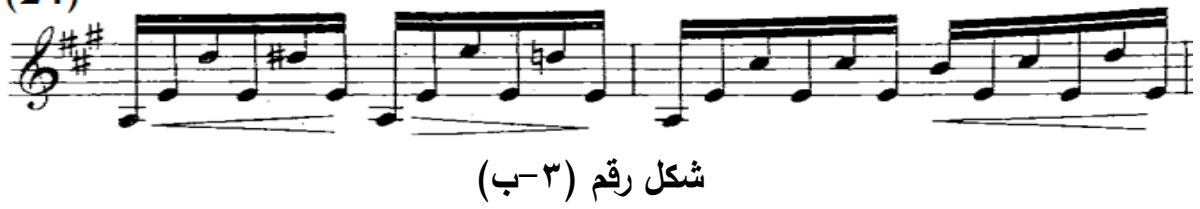

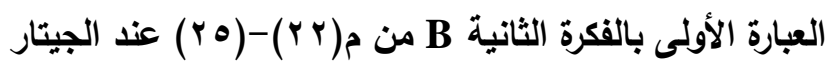

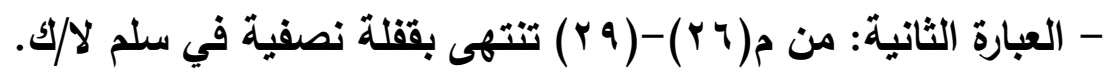
إعادة حرفية للعبارة الأولى بالفكرة الثانية، والثكلين التاليين رقم (ع-أ)،(ع-ب) يوضحان العبارة

الثانية بالفكرة الثانية عند كل من الفيولينة والجيتار .

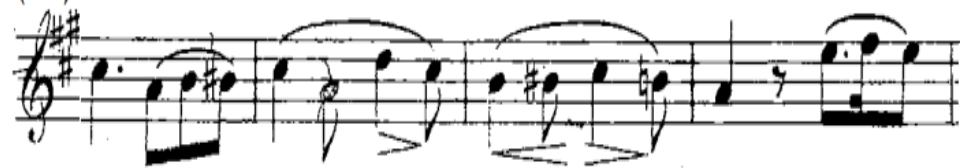

شكل رقم (ع - (أ)

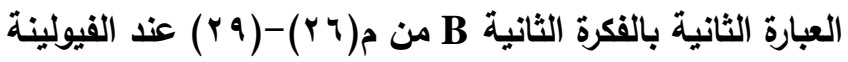

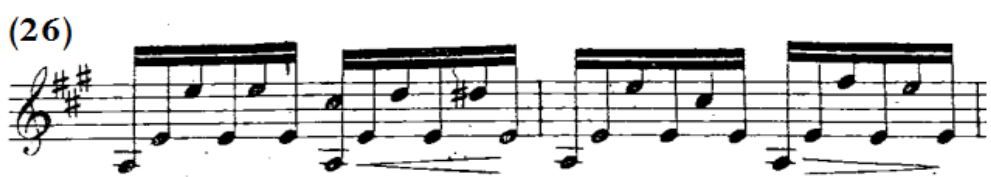

(28)

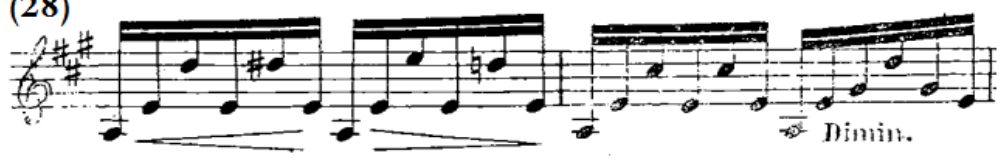

شكل رقم (ع-ب)

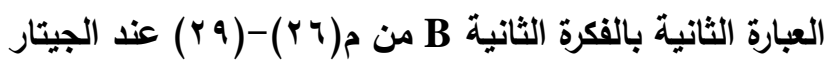

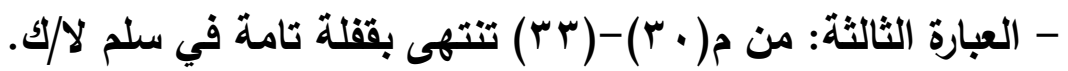

إعادة شبه حرفيـة للعبـارة الأولى بـالفكرة الثانيـة وتؤدى الفيولينـة في منطقة صـوتية منخفضـة،

والثكلين التاليين رقم (0-أ)،(0-ب) يوضـحان العبارة الثالثة بـالفكرة الثانية عند كل من الفيولينة والجيتار •

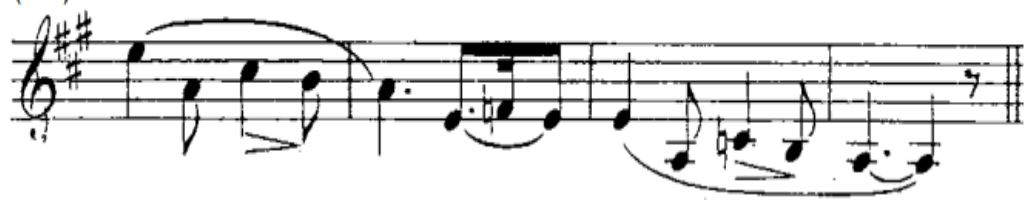

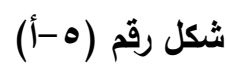

مجلة علوم وفنون الموسيقى - كلية التربية الموسيقية ـ المجلد الرابع و الأربعون -

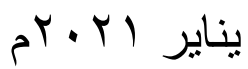


العبارة الثالثة بالفكرة الثانية B من م(·r)-(Tr) عند الفيولينة

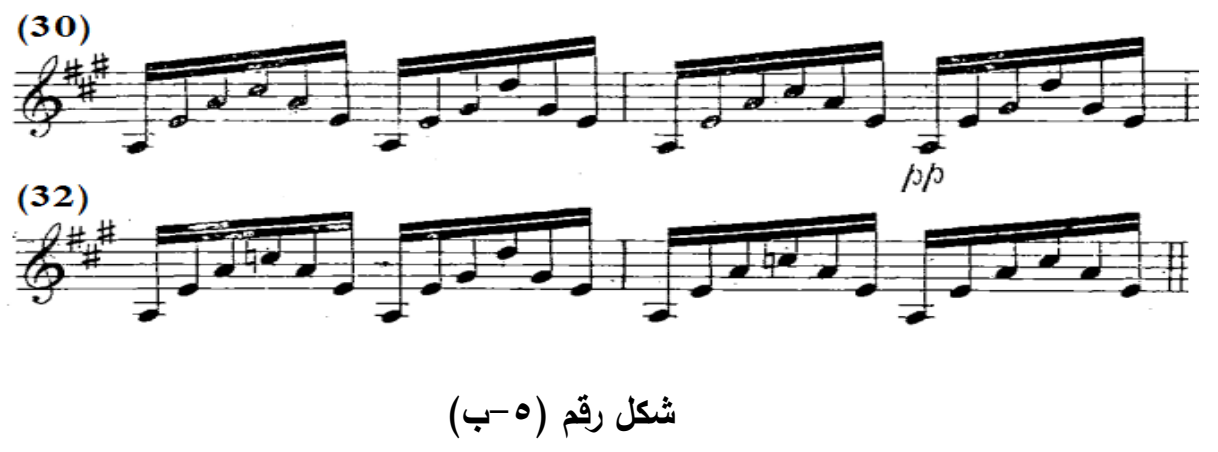

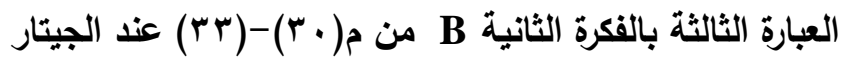

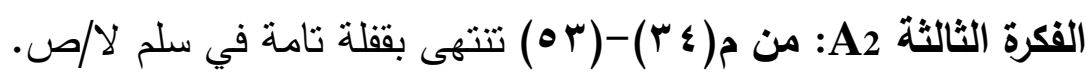
إعادة حرفية للفكرة الأولى وتتكون من جملتين جاءت كما يلي:

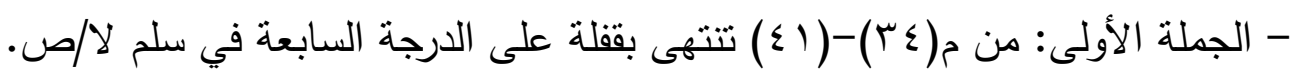

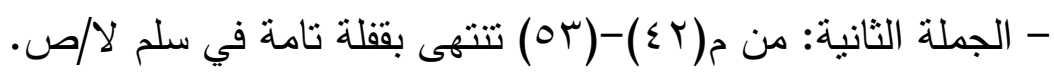

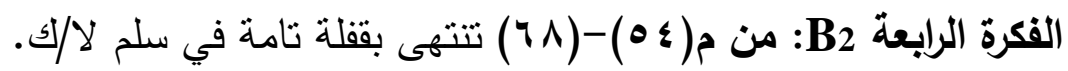
إعادة حرفية للفكرة الثانية وتتكون من ثلات عبارات جاءت كما يلي:

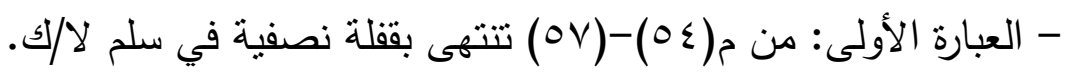

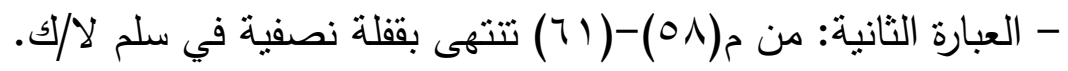

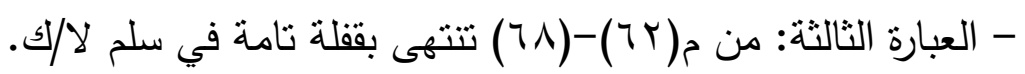

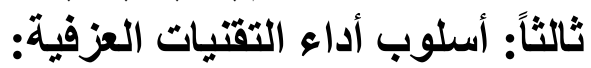

وسوف يقوم الباحث بتحديد التقتيات العزفية في اليد اليمنى ثم اليد اليسرى وتوضيح كيفية

أدائها ومصطلحات التعبير والأداء على النحو التالى:

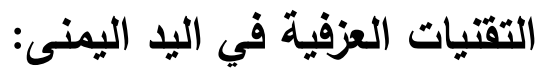
1- العزف المنفصل Detache:

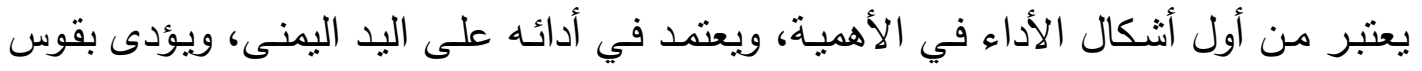

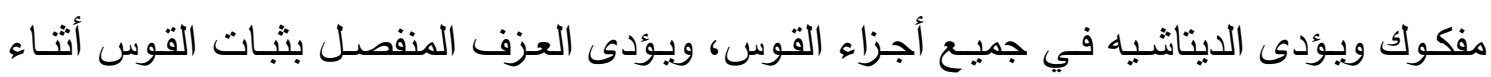

مجلة علوم وفنون الموسيقى - كلية التربية الموسيقية ـ المجلد الر ابع و الأربعون -

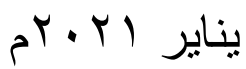


العزف، والمحافظة على ضغط شعر القوس على الوتز ، وخاصة في إستعمال القوس في الإتجاهين

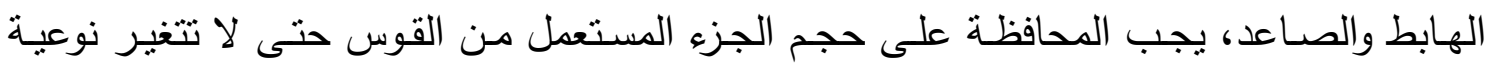

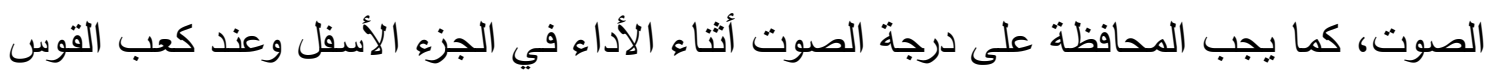

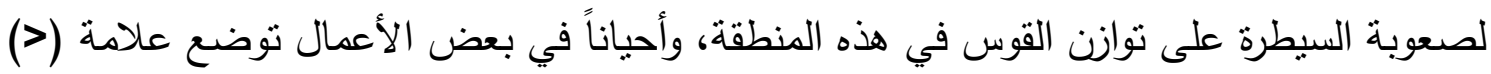
ويقصد بها الضغط في بداية الصوت، أو علامة (-) وتعني التأكيد عليها وإظهارها وينتج عنها لهاهيا

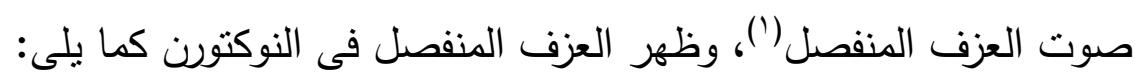
- في م(^) وإعادتها في م(· ؟ ).

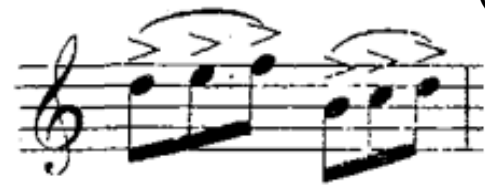

شكل رقم (7)

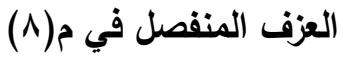

ب - العزف المتقطع Staccato:

هو صوت قصبر متقطع حاد الثخصية، ويكون القوس أثناء أدائه ثابتاً على الأوتار ، ويؤدى

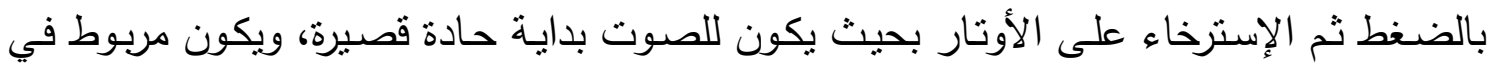

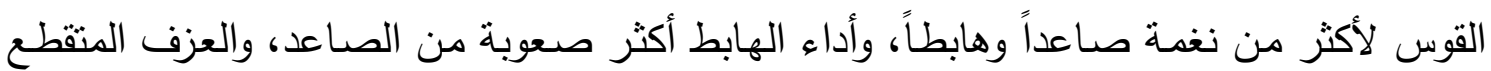

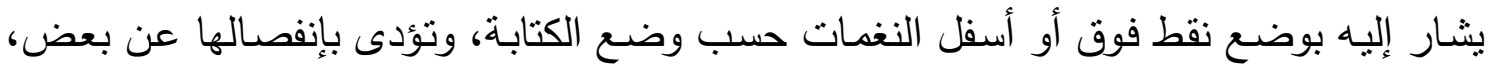

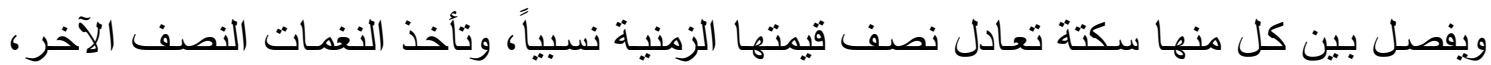

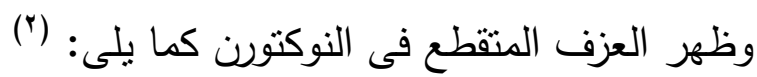

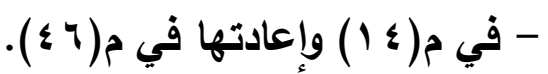

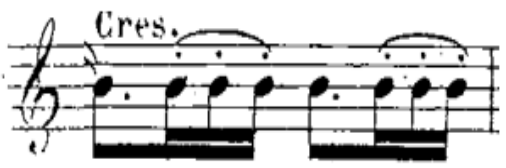

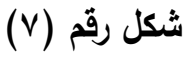

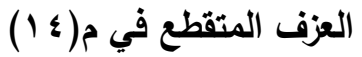

بegato - ب العزف المتصل ويقول "ليبولد آور": أن العزف المتصل واحد من تكنيكات القوس الأكثر إستخداماً، وإذا أتقن

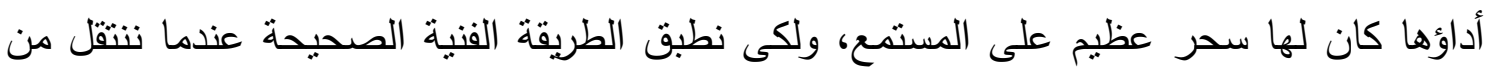

(1) Aure, Leopold: "Violin playing as I teach it", Dover press, New York, 1980, P.35.

${ }^{\text {(2) }}$ Flesh, Carl: "The Art of Violin playing", Carl Fischer, New York, 1939, P.54.

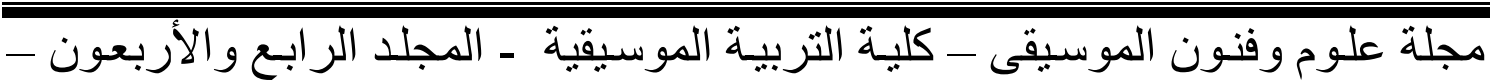

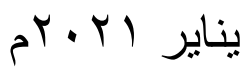


وتر لآخر أثثاء أداء العزف المتصل، فإن علينا أن نراعى إستخدام الرسغ بمساعدة من مقدمة

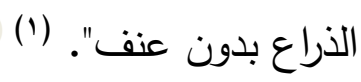
ويقول "كارل فليش": أن حركة العزف المتصل هي الحركة التي ليس فيها إنقطاع بين نغمة

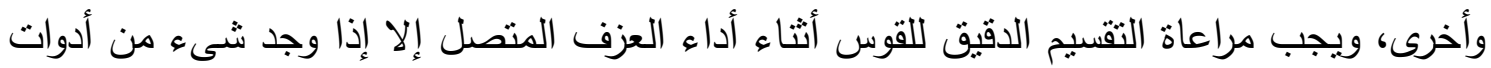

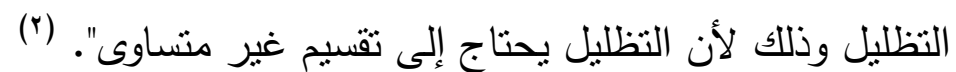
وقد ظهرت تقنية العزف المتصل في النوكتورن كما يلى: قوس لحنى متصل Legato:

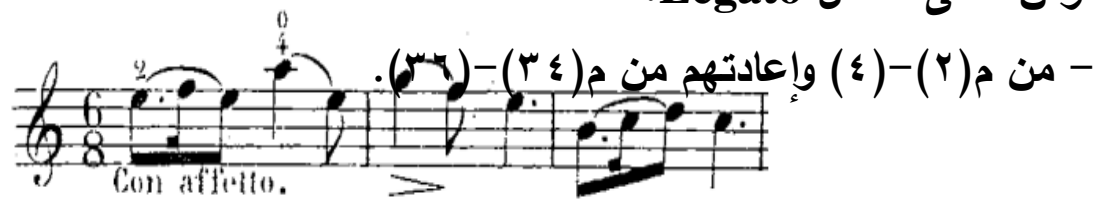

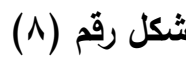

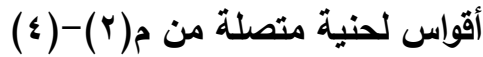

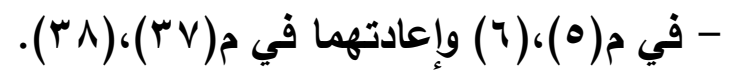

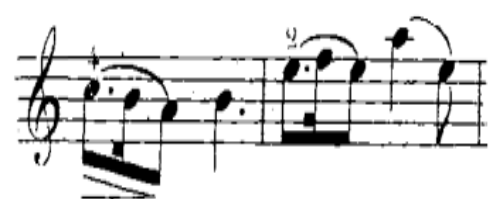

(9) شكل رقم (9)

أقواس لحنية متصلة في م(0)،(") (ه) - في م(^)،(9) وإعادتهما في م(• • )،(1) ).

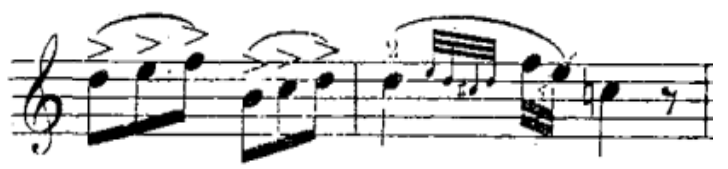

شكل رقم (·)

أقواس لحنية متصلة في م(^)،(9) (1) (1)

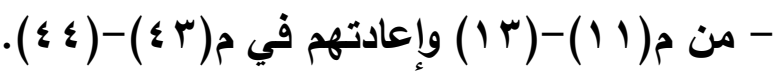

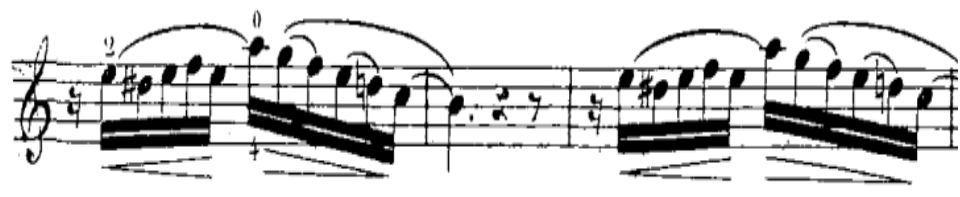

(1) Aure, Leopold: op.cit, 1980, P.31.

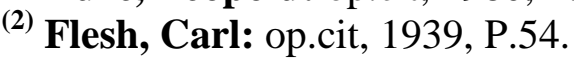

مجلة علوم وفنون الموسيقى - كلية التربية الموسيقية ـ المجلد الر ابع والأربعون -

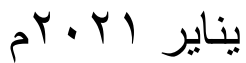


شكل رقم (11)

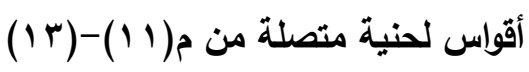

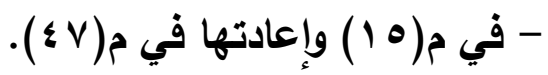

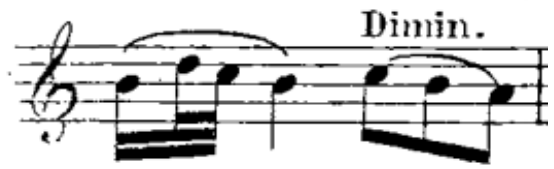

شكل رقم (ri (I)

أقواس لحنية متصلة في م(10)

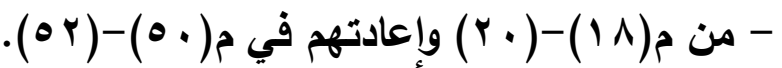

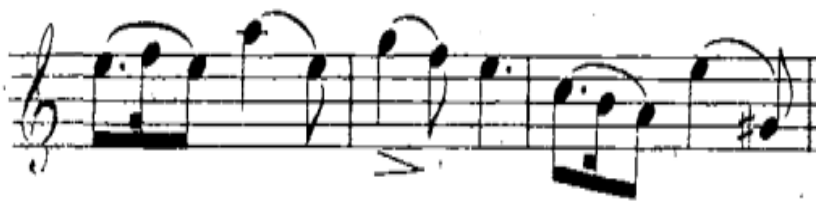

شكل رقم (T)

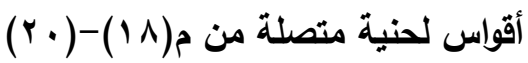

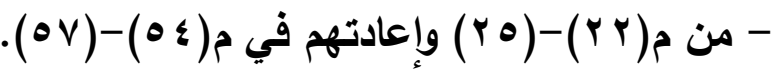

(22)

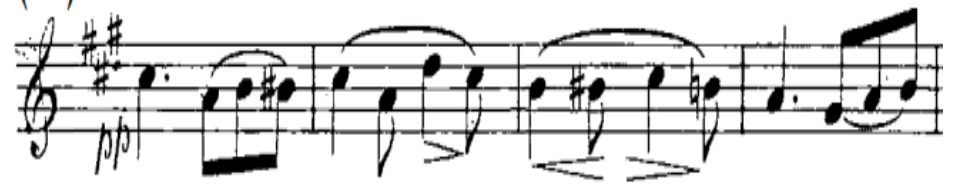

شكل رقم (ع ا)

أقواس لحنية متصلة من م(Y Y Y)-(Yo) (1)

(26)

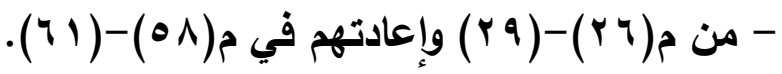

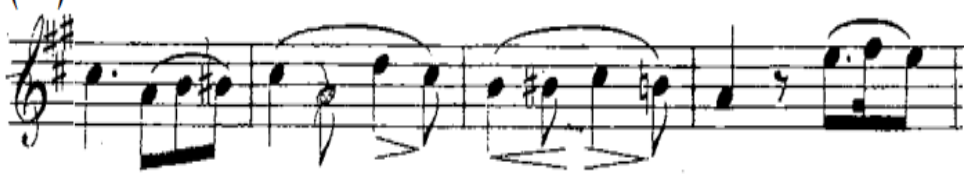

شكل رقم (10)

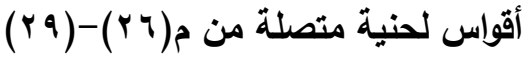

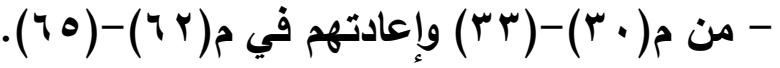

مجلة علوم وفنون الموسيقى - كلية التربية الموسيقية ـ المجلد الر ابع و الأربعون -

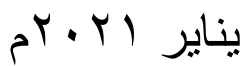


(30)

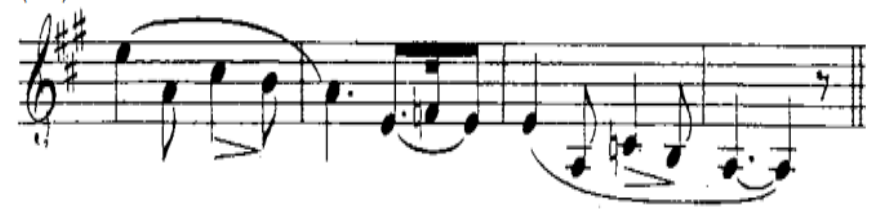

شكل رقم (17)

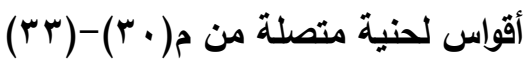

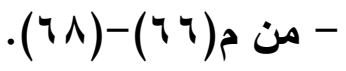

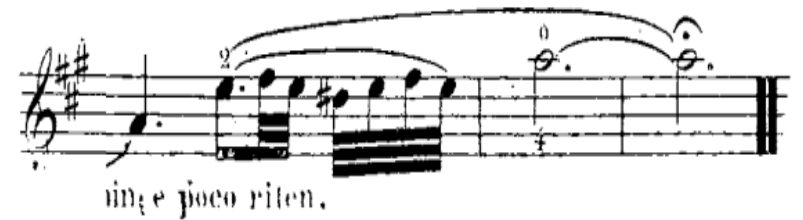

شكل رقم (iv)

أقواس لحنية متصلة من م(74)-(71)

أقواس لحنية قصيره لنغتين Slur:

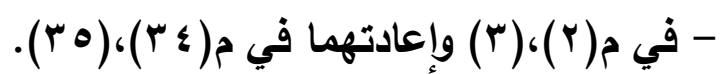

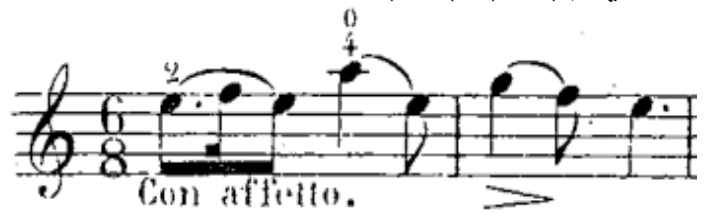

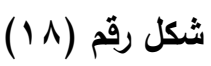

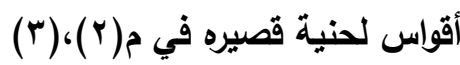

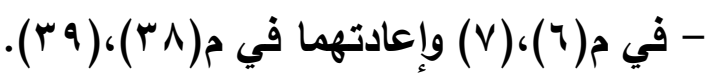

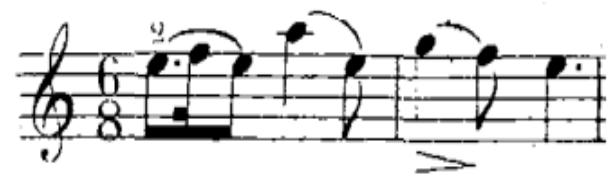

شكل رقم (19)

أقواس لحنية قصيره في م(Y)، (V)

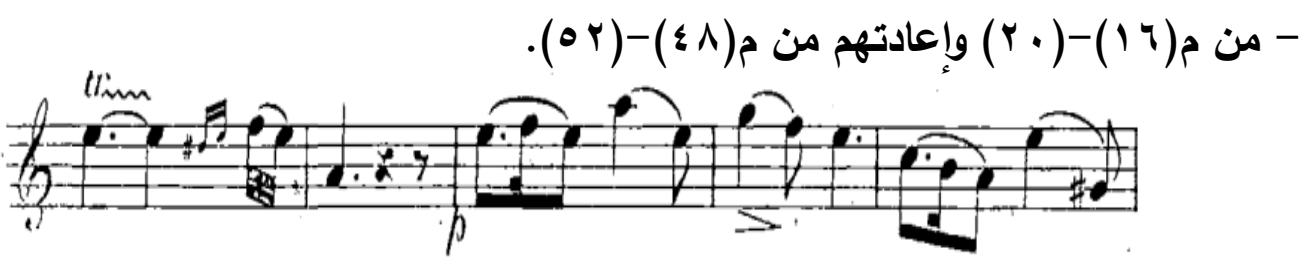

مجلة علوم وفنون الموسيقى - كلية التربية الموسيقية ـ المجلد الر ابع والأربعون -

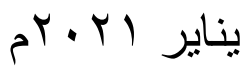




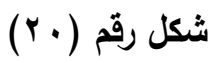

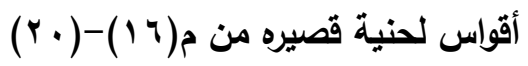

التقتيات العزفية باليد اليسرى:

اليد اليسرى هي الأداه المكمله لليد اليمنى، فلا يمكن فصلهما عن بعض أو التقليل من دور أحدهما، ويقول "فليش": بينما تهتم اليد اليمنى بإنتاج النغمات، فإن مهمة اليد اليسرى هي تغيير

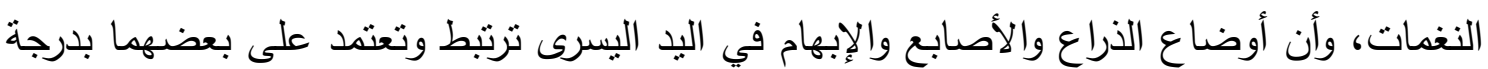

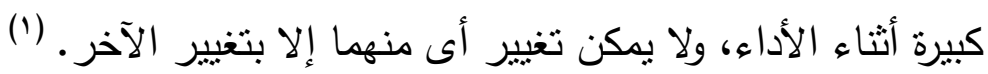

1- النغمات السلمية Scales:

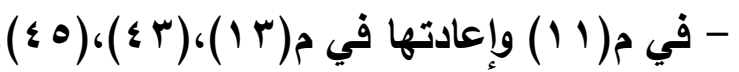

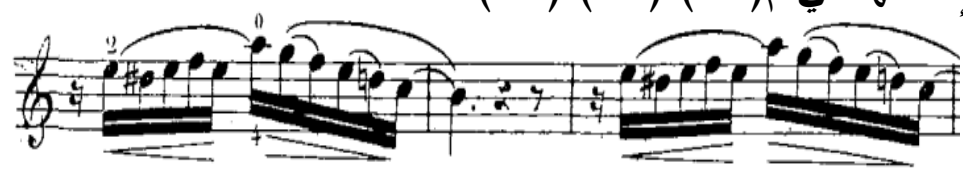

شكل رقم (r)

نغمات سلمية هابطة في م(1)

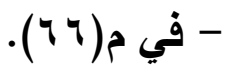

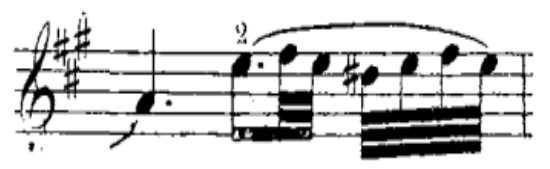

شكل رقم (rr)

نغمات سلمية صاعدة في م(T) (TY)

: بrnaments الحليات

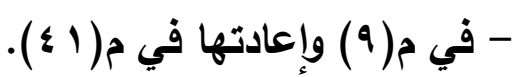

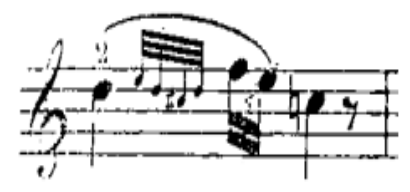

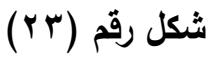

حلية الأبوجاتورا في م(9) (9) (9)

- في م(7 ا ) وإعادتها في م(1 \&).

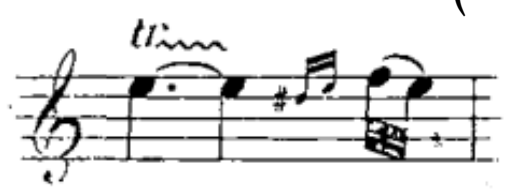

${ }^{(1)}$ Flesh, Carl: Ibd, 1939, P.31.

مجلة علوم وفنون الموسيقى - كلية التربية الموسيقية ـ المجلد الر ابع و الأربعون -

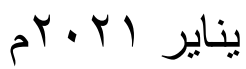


شكل رقم (ع

حلية الأبوجاتورا في م(1) (1) (1)

- في م(4 1 ) وإعادتها في م(1 ؛ ).

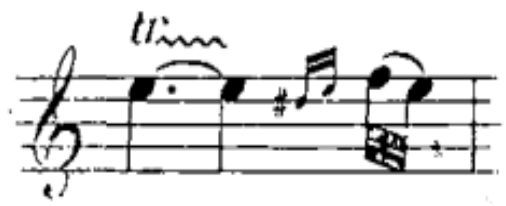

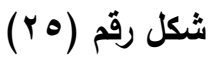

حلية التريل في م(17) - (17) - (19)

ب- بلفلاوتاتو Harmonics:

الفلاوتاتو أو الفلاجوليت أو الهارمونيكس، هى ثلاث مرادفات لمعنى واحد، هو محاكاه

الصوت الفلوت أب صوت الصفير ، ويحدث هذا الصوت بطريقتين كالآتى:

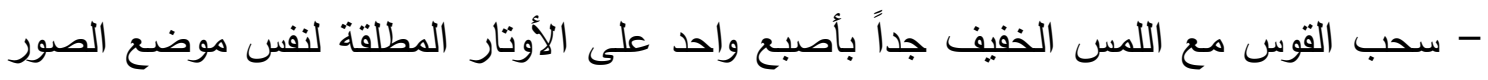

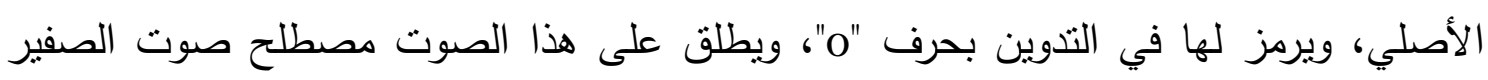

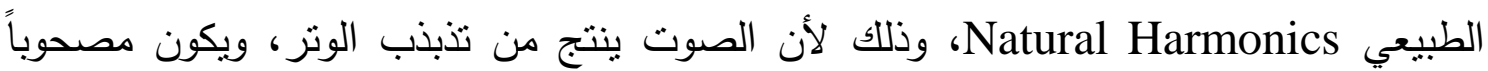
بسلسلة من النغمات النوافقية التي لا تميزها الأذن.

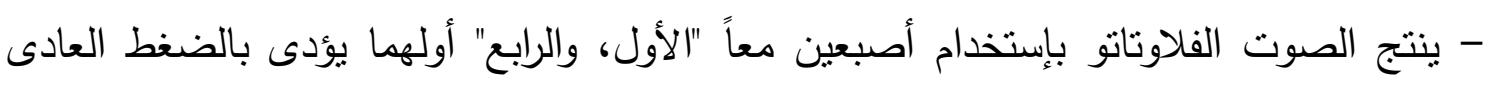

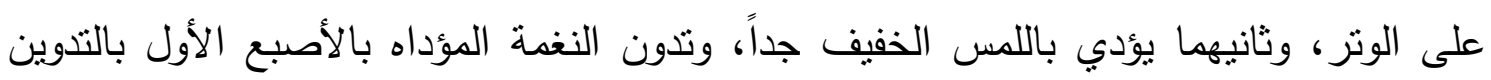

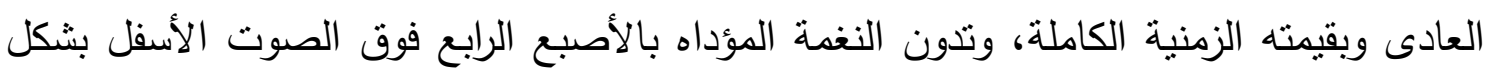

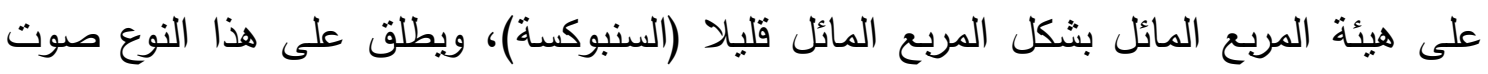

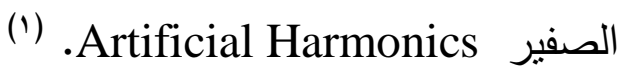

ويقول "نامبولسكي": الفلاوتانو الطبيعي ينتج عن لمس الأصبع للوتر المهتز، وعلى سبيل المثال إذا قسمنا وتز "صول" إلى نصفين منساويين، ثم لمسنا الوتر وهو مهتز عند منتصفه، تتنج

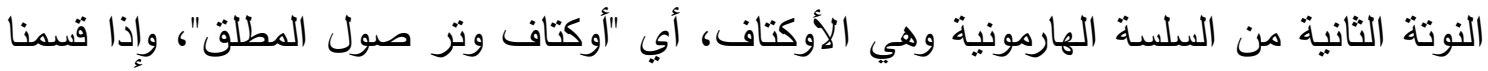

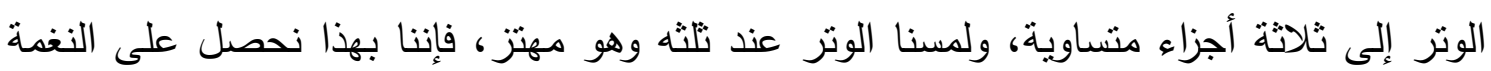

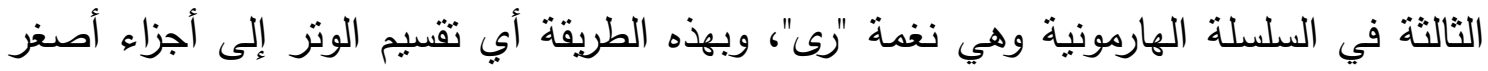

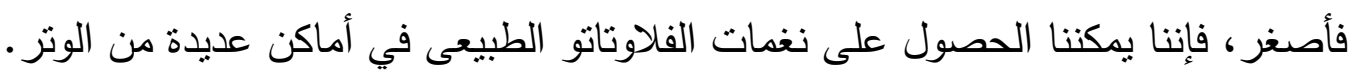

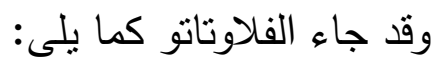

(1) Aure, Leopold: Ibd, P.175.

مجلة علوم وفنون الموسيقى - كلية التربية الموسيقية ـ المجلد الر ابع و الأربعون -

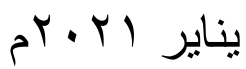




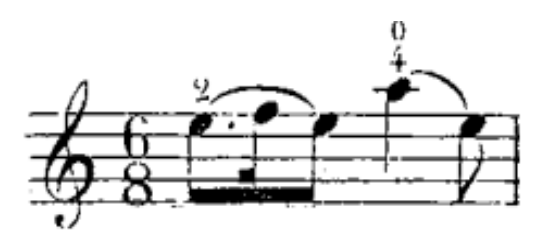

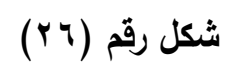

الفلاوتاتو في م(ץ)

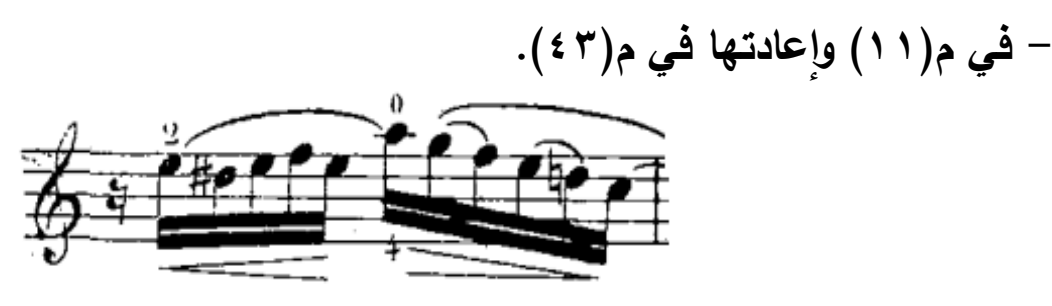

شكل رقم (YV)

الفلاوتاتو في م(1)

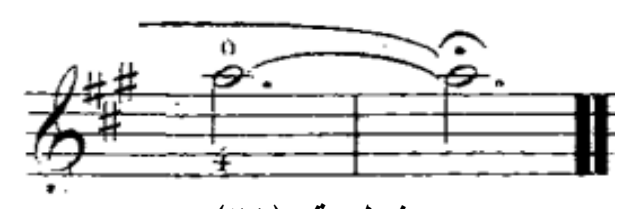

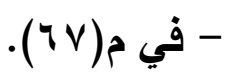

شكل رقم (Y^)

(الفلاوتاتو في م(TV)

المصطلحات التعبيرية والأدائية: والجدول التالى يوضح ذلك.

\begin{tabular}{|c|c|}
\hline معانى المصطلحات وأماكن ظهورها & مصطلحات التعبير \\
\hline الأداء بتأثر وعاطفة، وظهر فى م(Y). & Con affeto \\
\hline أداء خافت جداً ويختصر الى (pp) ظهر فى م(Y r). & Piano Piano \\
\hline 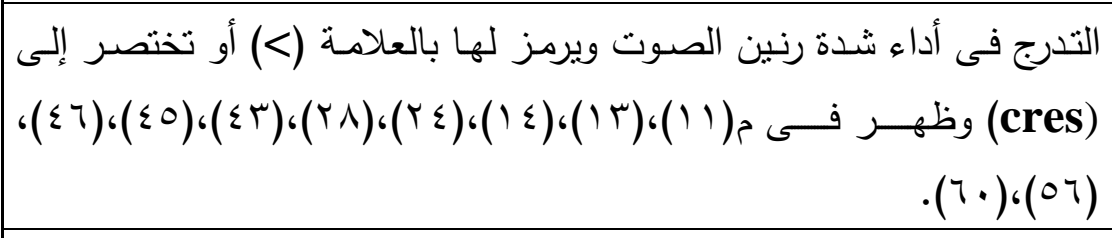 & crescendo \\
\hline 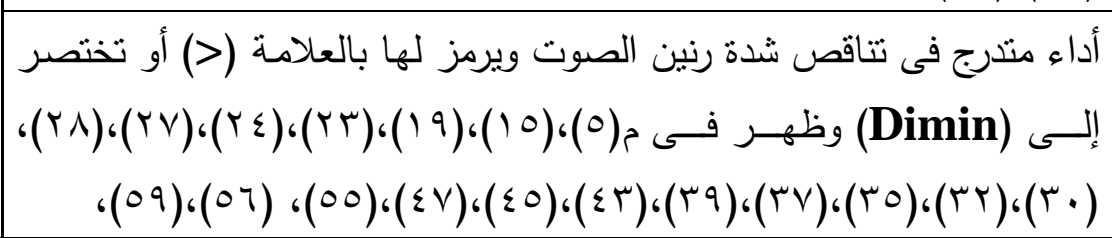 & diminuendo \\
\hline
\end{tabular}

مجلة علوم وفنون الموسيقى - كلية التربية الموسبقية ـ المجلد الر ابع و الأربعون -

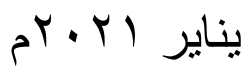




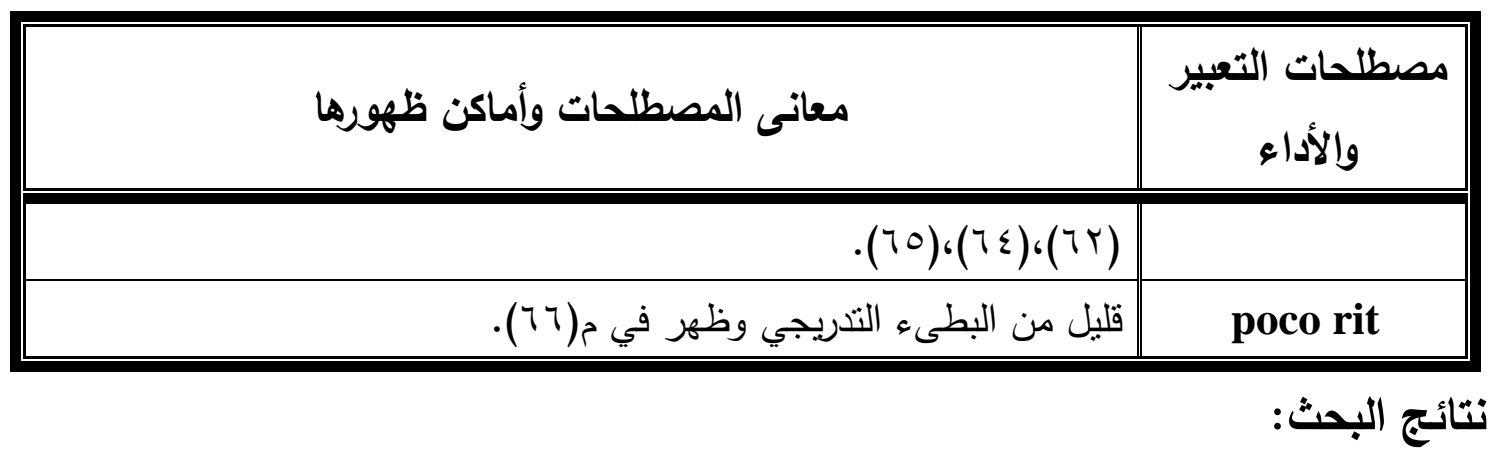

بعد أن قام الباحث بالتحليل البنائي والعزفي لنوكتورن رقم ( () للفيولينة والجيتار عند فريدريش برجمـولر فـي الإطـار التطبيقى، وقـام بتحديــ التقنبـات العزفيـة بالمؤلفـة وتوضـيح كيفيـة أدائهـا ومصطلحات التعبير والأداء، وقد توصل الباحث إلى النتائج التي جاءت تحقيقاً لأهداف البحث ورداً على أسئلته على النحو التالي:

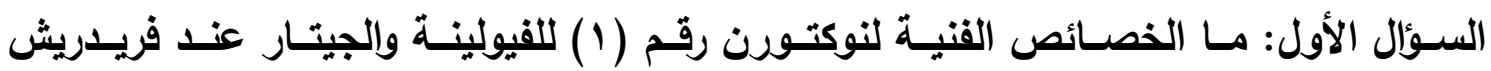
برجمولر? واستطاع الباحث الإجابة على السؤال الأول بالإطار التطبيقى واستخلاص الخصائص الفنية من خلال التحليل البنائي والعزفي للنوكتورن، وجاءت كما يلي: أولاً: نتائج التحليل البنائي: ا- جاءت الفكرة الأولى والثالثة بالنوكتورن رقم (1) عند فريدريش برجمولر في سلم لا/ص، وجاءت الفكرة الثانية والرابعة في سلم لا/ك. ץ- جاءت السرعة ثابتة طوال النوكتورن مع ظهور إطالة المدة الزمنية في الختام م(؟^)، وإستخدام التبطىء التدريجى rit في م(7 7) قبل نهاية النوكتورن. r- إستخدم برجمولر ميزان ثنائي مركب ثابت طوال النوكتورن. ع - جاءت النوكتورن عند عازف الفيولينة في النسيج البوليفوني. 0 جاءت النوكتورن في صيغة ثنائية مع التكرار A,B,A2,B2. ثانياً: نتائج التحليل العزفي: اعن إعتمد لحن الفيولينة في النوكتورن على: 1 - لحن قائم على مسافات لحنية صاعدة وهابطة. Y- لحن قائم على نغمات مفردة متكررة. r- لحن قائم على نغمات سلمية هابطة وصاعدة. ع - لحن من نغمات مفردة يسبقها حلية الأبوجاتورا وخاضعة لحلية التريل.

مجلة علوم وفنون الموسيقى - كلية التربية الموسيقية ـ المجلد الر ابع و الأربعون -

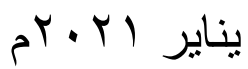


السؤال الثاني: ما كيفية أداء نوكتورن رقم (1) للفيولينة والجيتار عند فريدريش برجمولر؟

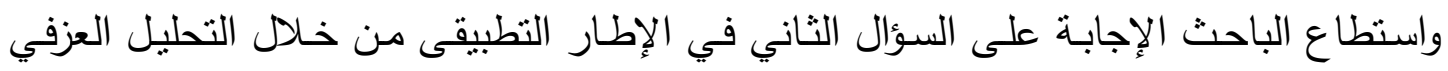

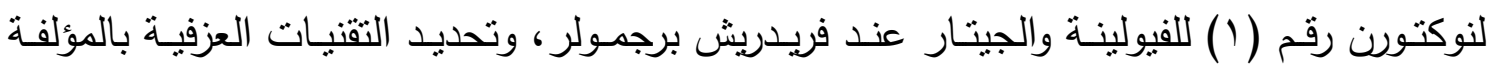
وتوضيح كيفية أدائها، وجاءت التثنيات كما يلى: نتائج أساليب الأداء والتعبير: وهي عبارة عن التقنيات العزفية في اليد اليمنى واليد اليسرى ومصطلحات التعبير في النوكتورن رقم ( ) للفيولينة والجيتار عند فريدريش برجمولر وجاءت كما يلى: 1 التقنيات العزفية في اليد اليمنى: الئن (العزف المنفصل Detache - العزف المنقطع - Mezzo Staccato - العزف المتصل .(Legato,Slur r - التقتيات العزفية في اليا اليسرى:

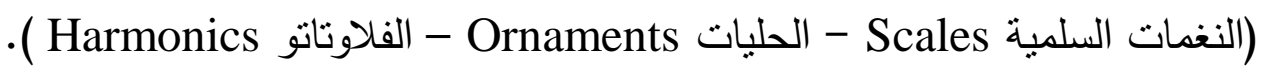

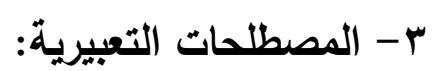
- Con affeto : الأداء بصوت خافت جداً. : pp - dim - التدرج من الصوت القوى إلى المنخفض. (القهن - cres توصيات البحث:

ا - تزويد مكتبـة الكليـة والمكتبـة الصـوتية بالمدونات الموسيقية والإسطوانات لمؤلفـات الفيولينـة الكتتوعة بمصاحبة آلة الجيتار في العصور المختلفة.

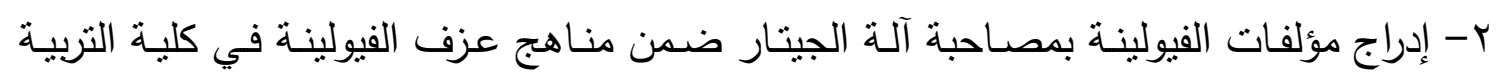
الموسيقية - جامعة حلوان. r- تشجيع دارسى الكلية علي أداء نوكتورن الفيولينة والجيتار عند فريدريش برجمولر .

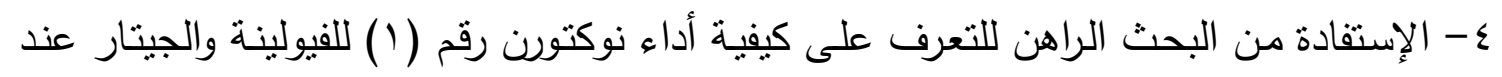
فريدريش برجمولر ·

مجلة علوم وفنون الموسيقى - كلية التربية الموسيقية ـ المجلد الر ابع و الأربعون -

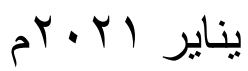




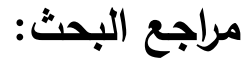 \\ أولاً: المراجع العربية: المبح:}

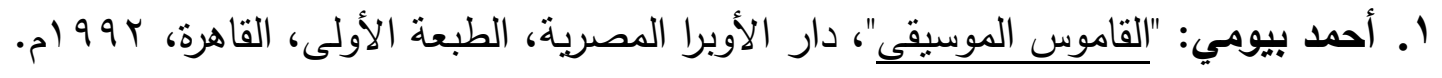

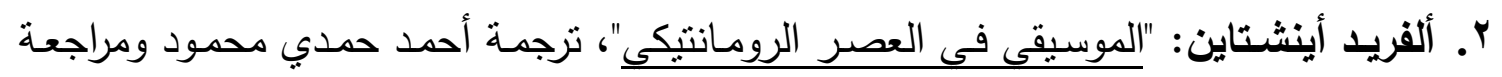

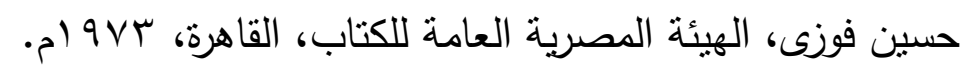

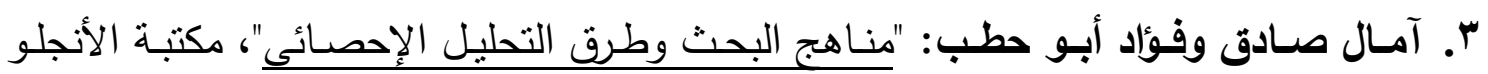

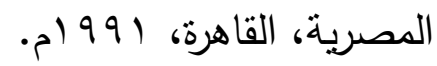

ثانياً: المراجع الأجنيبة: المرة،

4. Achard, Ken: "The History and development of the American Guitar", Bold Strummer Press, U.S.A, 1996.

5. Apel, Wille: "Harvard Dictionary of Music", Second Edition, the Belknap Press of Harverd University Press, Cambrige, London, 1979.

6. Aure, Leopold: "Violin playing as I teach it", Dover publication, Inc, New York, 1980.

7. Flesh, Carl: "The Art of Violin playing", Book One, Carl Fischer, New York, 1939.

8. Randal, Don Michel: "The Harvard Dictionary of Music", 2th Edition, Harvard University Press, London, 2003.

9. Sadie, Stanly: "The New Grove Dictionary of Music and Musician", Macmillan Publishers Limited, U.S.A, 2001.

مجلة علوم وفنون الموسيقى - كلية التربية الموسيقية ـ المجلد الر ابع و الأربعون -

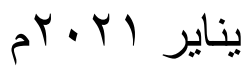




\section{ملخص البحث}

كيفية أداء نوكتورن رقم ( ) للفيولينة والجيتار عند فريدريش برجمولر

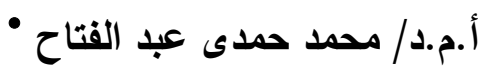

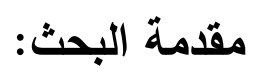

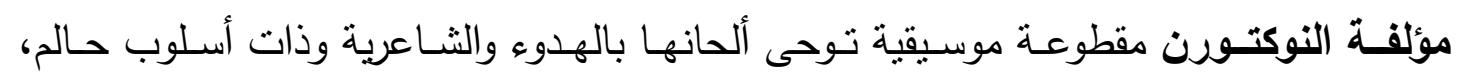

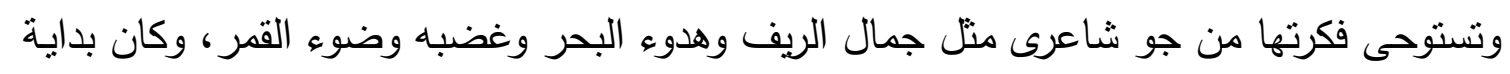

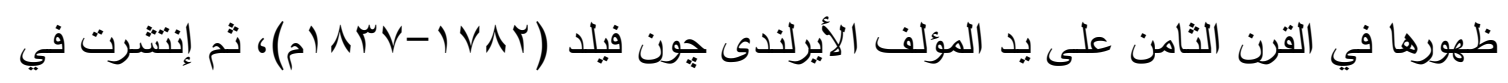

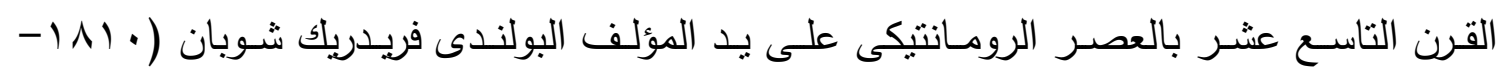

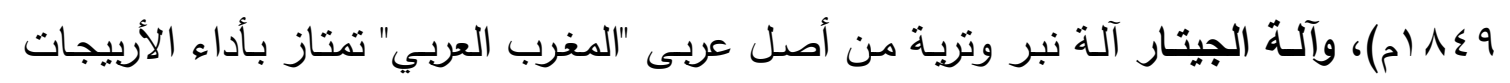

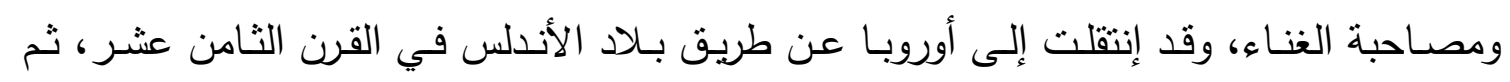

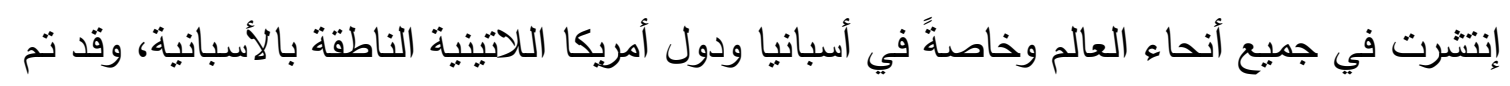

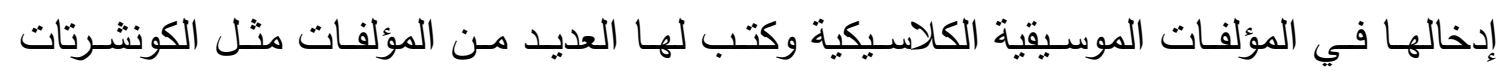

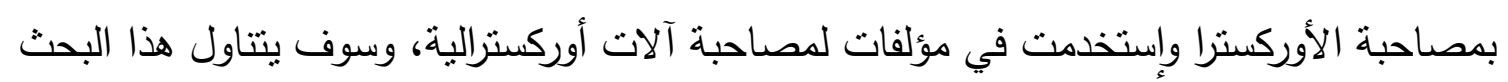

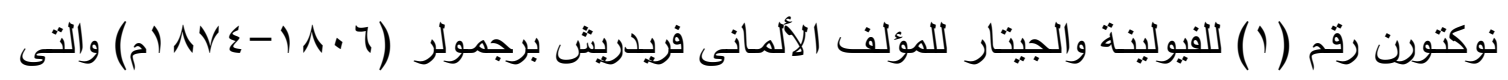

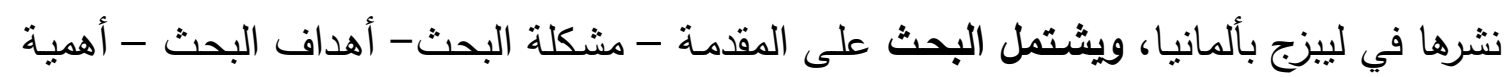

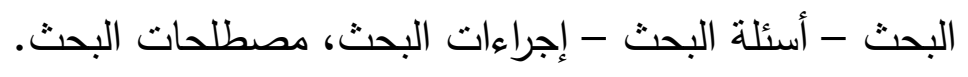

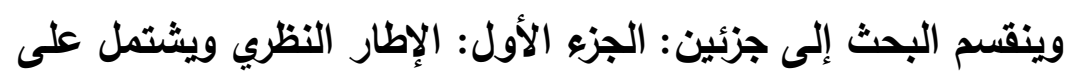

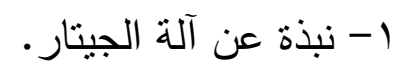

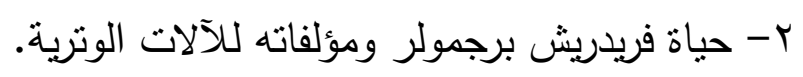
الجزء الثاني: الإطار التطبيقي ويشتمل على لئل

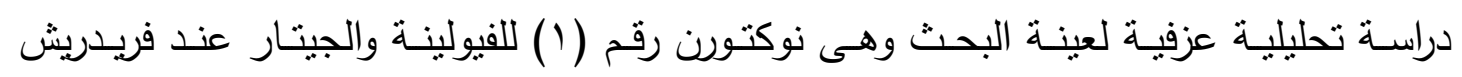

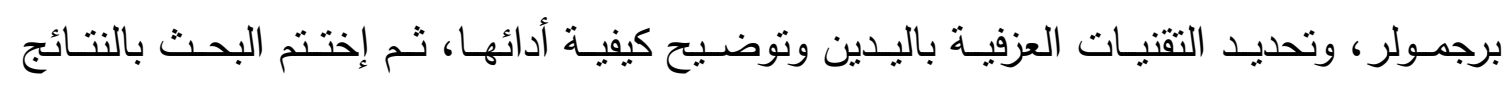
والنوصيات والمراجع العربية والأجنبية وملخص البحث باللغة العربية والأجنبية.

• أستاذ مساعد بقسم الأداء - شعبة أوركترالي - كلية التربية الموسيقية - جامعة حلوان.

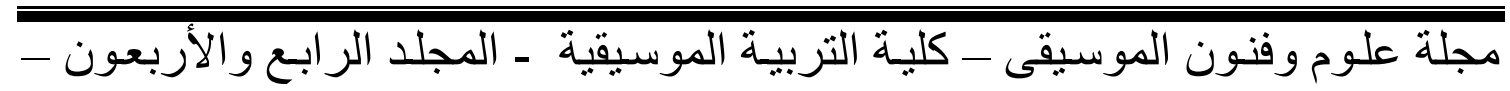

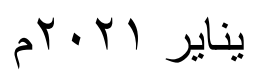




\section{Abstract of the Research \\ How to Perfomance Nocturne No.1 for Violin and Guitar by Friedrich Burgmüller}

\section{- Mohamed Hamdy Abdel Fatah}

The Nocturne is a musical piece that inspires the melody to be calm, poetic and dreamy, her idea is inspires by a poetic atmosphere such as the beauty of the countryside, the calmes of the sea, its anger, and moonlight, the beginning of its appearance in th $18^{\text {th }}$ century by irish composer John Field (1782-1837), then speard in $19^{\text {th }}$ century in the Romantic era bt the Polish composer Frédéric Chopin (1810-1849), The Guitar is astring instrument with Arabic origins, which is distinguished by the performance of the arppigio and accompanied by singing, it moved Europe through the country of Andalusia in the $18^{\text {th }}$ century, then it speard all over the world, specially Spain and the Spanish- speaking Latin America countries, it has been include in classical music compositions, many compositions have been written for it, such as concertos with accompanying the orchestra and it has been used in compositions to accompany orcgestral instruments, this research deals with Nocturne No.1 for Violin and Guitar by Friedrich Burgmuller (1806-1874) which was published in Germany.

The research includes: Introduction, Problem, Objectives, Importance, Questions, Procedures and terms of the Research.

\section{The research divided into:}

First Part: Theoretical frame; its includes

- Historical About Guitar.

-The Biography and Strings Compositions of Friedrich Burgmuller .

Second Part: Applied Frame; its includes

An Analytical study of Mocturne No.1 for Violin and Guitar by Friedrich Burgmuller and identify the performing techniques and clarify the how to performance it, Then the research concluded the results, recommendations, references in Arabic and Foreign, Abstract of the research Arabic.

\footnotetext{
* Assistant Professorin the Performance Department, Violin Division, Faculty of Music Education, Helwan University.

مجلة علوم وفنون الموسيقى - كلية التربية الموسيقية ـ المجلد الر ابع و الأربعون -

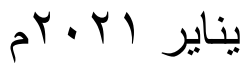

